\title{
Modeling Elementary Heterogeneous Chemistry and Electrochemistry in Solid-Oxide Fuel Cells
}

\author{
Huayang Zhu, ${ }^{\text {a,* }}$ Robert J. Kee, ${ }^{\text {a, }, \text {, }}$ Vinod M. Janardhanan, ${ }^{\text {b }}$ \\ Olaf Deutschmann, ${ }^{\mathrm{b}, *}$ and David G. Goodwin ${ }^{\mathrm{c}}$ \\ ${ }^{a}$ Engineering Division, Colorado School of Mines Golden, Colorado 80401, USA \\ ${ }^{b}$ Institute for Chemical Technology, University of Karlsruhe, Karlsruhe, Germany \\ ${ }^{c}$ Engineering and Applied Science, California Institute of Technology Pasadena, California 91125, USA
}

This paper presents a new computational framework for modeling chemically reacting flow in anode-supported solid-oxide fue cells (SOFC). Depending on materials and operating conditions, SOFC anodes afford a possibility for internal reforming or catalytic partial oxidation of hydrocarbon fuels. An important new element of the model is the capability to represent elementary heterogeneous chemical kinetics in the form of multistep reaction mechanisms. Porous-media transport in the electrodes is represented with a dusty-gas model. Charge-transfer chemistry is represented in a modified Butler-Volmer setting that is derived from elementary reactions, but assuming a single rate-limiting step. The model is discussed in terms of systems with defined flow channels and planar membrane-electrode assemblies. However, the underlying theory is independent of the particular geometry. Examples are given to illustrate the model.

(C) 2005 The Electrochemical Society. [DOI: 10.1149/1.2116607] All rights reserved.

Manuscript received May 4, 2005; revised manuscript received August 8, 2005. Available electronically November 4, 2005.

Solid oxide fuel cells (SOFC) can be operated with a variety of fuels, including hydrogen, $\mathrm{CO}$, hydrocarbons, or mixtures of these. This is possible because of the relatively high operating temperatures, and, at least in conventional SOFC anodes, the use of transition metal catalysts that promote the water-gas-shift reaction

$$
\mathrm{CO}+\mathrm{H}_{2} \mathrm{O} \rightleftharpoons \mathrm{CO}_{2}+\mathrm{H}_{2}
$$

and steam reforming, which for methane may be written globally as

$$
\mathrm{CH}_{4}+\mathrm{H}_{2} \mathrm{O} \rightleftharpoons \mathrm{CO}+3 \mathrm{H}_{2}
$$

If sufficient steam is produced electrochemically at the anode/ electrolyte interface by the reaction

$$
\mathrm{H}_{2}+\mathrm{O}^{2-} \rightleftharpoons \mathrm{H}_{2} \mathrm{O}+2 \mathrm{e}^{-}
$$

then reforming and shifting can, in principle, lead to full (if indirect) electrochemical oxidation of a hydrocarbon fuel.

However, competing reaction pathways catalyzed by transition metals may also lead to solid carbon deposition, which can quickly destroy the anode. For this reason, some degree of upstream fuel processing, eiher by catalytic partial oxidation or by steam reforming, is usually used to produce a fuel stream that is rich in $\mathrm{H}_{2}$ and $\mathrm{CO}$ and dilute in residual hydrocarbons before reaching the SOFC. Because upstream processing adds to the complexity, size, and cost of the overall plant, it is of considerable interest to minimize or even eliminate the need for it. There is evidence that mixing some oxygen with a hydrocarbon fuel can deliver good performance. ${ }^{1}$ In this case there must be partial oxidation within the anode structrue. Another promising alternative to utilize hydrocarbon fuels "directly" in SOFCs is to use a ceria oxidation catalyst instead of a transition metal. $^{2}$

Whether an SOFC uses a "reforming anode" with a transition metal catalyst, or a "direct oxidation" anode with a ceria-based catalyst, or perhaps uses a different, novel anode design, optimizing the system to run efficiently on hydrocarbon or hydrocarbon-derived fuels is a very challenging problem, due to the complex, coupled physico-chemical processes involved. When significant $\mathrm{CO}$ and/or hydrocarbons are present in the fuel, models must also account for the in situ production of hydrogen through reforming and shifting reactions within the anode, as well as solid-carbon formation.

Many questions of interest for optimization studies cannot currently be answered easily. For example, for a given anode design, what degree of upstream fuel processing is required to avoid carbon deposition, and how does this depend on operating conditions? What

\footnotetext{
Electrochemical Society Active Member.

z E-mail: rjkee@mines.edu
}

anode design (choice of catalyst, anode thickness, porosity, etc.) minimizes the need for upstream fuel processing? What is the effect of fuel depletion, load conditions, temperature, or flow rates? An anode might be functionally graded through its thickness; what grading of porosity or catalyst loading is optimal?

In practice, questions like these are usually answered by extensive testing, often with minimal guidance from theory. Clearly, the ability to provide some answers to questions such as these based on an understanding of the underlying chemical and physical processes, even if approximate, is of great value in reducing the time and expense associated with SOFC development.

Although the present state of knowledge of the physical and chemical processes responsible for SOFC performance is incomplete, enough is known to begin to put together physically based models that can integrate experimental data from multiple sources, and make useful engineering performance predictions. For example, results from pattern-anode studies of hydrogen oxidation at Ni-YSZ anodes have led to mechanistic insights into the mechanism of charge transfer; these insights may be applied to construct activation polarization models for Ni-YSZ cermet anodes that may be used in place of semiempirical models. Also, detailed studies of the heterogeneous kinetics of shifting and reforming chemistry on transition metals have been carried out; the resulting reaction mechanisms can be used directly in SOFC models, provided they are constructed in a manner that allows use of detailed reaction mechanisms.

In this paper, we present a modeling framework for SOFC simulation that is a step toward the physically based, predictive, quantitative models that are needed for SOFC optimization and design Unlike most existing SOFC models that rely heavily on empirical systems-level data, here we begin at the microscale, incorporating what is known about important elementary steps (charge transfer, heterogeneous chemistry, porous media transport) into the model in a manner that accounts for the strong nonlinear couplings between them, and that allows assessing the sensitivity of macroscale performance: open circuit potentials, current-voltage characteristics, fuel utilization, efficiency, etc., to microscale phenomena.

Our focus is particularly on SOFCs using reforming anodes, but the approach applies generally to direct-oxidation anodes as well with minor modifications. The model takes as input a set of physical, chemical, and operating parameters (channel dimensions, reaction rates, electrode porosity, load potential, fuel composition and flow rates, etc.), and produces as output measurable performance parameters: current density profiles, efficiencies, exhaust gas compositions, that can be compared to experiment.

Developing physically based models of processes as complex as SOFCs is inevitably an iterative process, incorporating new information as it is available. Basing the model on fundamental physics 
and chemistry enables simulating a wider range of conditions than is possible with more empirical models. However, validation and refinement of model assumptions and parameter values is required at every step of the process. The approaches discussed in this paper provides a starting point and a framework that is capable of enhancement and refinement as new fundamental data become available.

Prior SOFC modeling. - In very broad terms, SOFC modeling is pursued along three general avenues. Stack level models are based on three-dimensional computational fluid dynamics (CFD) capabilities, often using commercial software packages (e.g., Fluent, STAR$\mathrm{CD})$. These models, which couple fluid flow, conductive and radiative heat transfer, and chemistry, are used to assist system design. ${ }^{3-7}$ Such models accommodate complex flow passages and cell layouts. In addition to electrochemical performance, predicting temperature distributions, pressure drops, and stress distributions is also important.

A number of investigators have developed models to study flow and chemistry within porous cermet composite electrodes. ${ }^{8-16}$ These models may include the gas-phase species transport through the pore phase, surface diffusion of adsorbed species, Ohm's law for the charge transport within the ionic and electronic conducting phases, charge balance, and charge-transfer kinetics. The models are formulated in a continuum differential-equation setting, and usually in one spatial dimension through the electrode thickness. Such models are used to investigate the effects of electrode structure and material properties on membrane-electrode assembly (MEA) performance.

Several groups have developed microscopic models to study charge-transfer processes in the vicinity of three-phase boundaries. ${ }^{17-27}$ These TPB models may include adsorption/ desorption of the gas-phase species, surface reactions and diffusion of the adsorbed species, and the charge-transfer electrochemical reactions. The geometrical setting may represent patterned electrodes or may consider a few individual particles of a cermet. These models are very helpful in the interpretation of electrochemical impedance spectroscopy (EIS) measurements or polarization measurements.

With only a few exceptions, the charge-transfer kinetics in all these models begins with a Nernst potential based on gas-phase composition and activation overpotentials represented in ButlerVolmer form. Thermal chemistry is usually handled with significant simplifying assumptions, such as global reaction kinetics or local equilibration of reforming and water-gas-shift chemistry. The work reported in the present paper emphasizes the incorporation of elementary chemical kinetics.

\section{Model Description}

Although much of the modeling approach described here could be used with any SOFC configuration, we focus in this paper on one specific configuration: a planar, anode-supported SOFC with a defined-channed coflowing architecture, as illustrated in Fig. 1. A fuel mixture flows from left to right in the fuel channel at the top, and is transported into the pores of the anode by a combination of Fickian and Knudsen diffusion together with convective Darcy flow. Within the anode it may undergo reaction on the catalyst-particle surfaces, and one or more species in the fuel mixture, either initially present or created in situ, may be electrochemically oxidized upon reaching the inner region of the anode near the dense electrolyte. We assume here that this electrochemically active region is much thinner than the total anode thickness, limited by the need to conduct oxygen ions from the dense electrolyte through the oxide particle pore network. In an anode-supported architecture the porous anode is on the order of a millimeter thick. The charge-transfer region is comprised of distributed three-phase interfaces limited to a few micrometers. ${ }^{9}$ Thus, on the scale of the relatively thick anode structure, the charge-transfer region can be approximated as a thin interface. The electrons produced by electrochemical oxidation reactions are collected by the network of electronically conducting particles (e.g., $\mathrm{Ni}$ or $\mathrm{Cu}$ ), which may or may not be the same as the catalyst

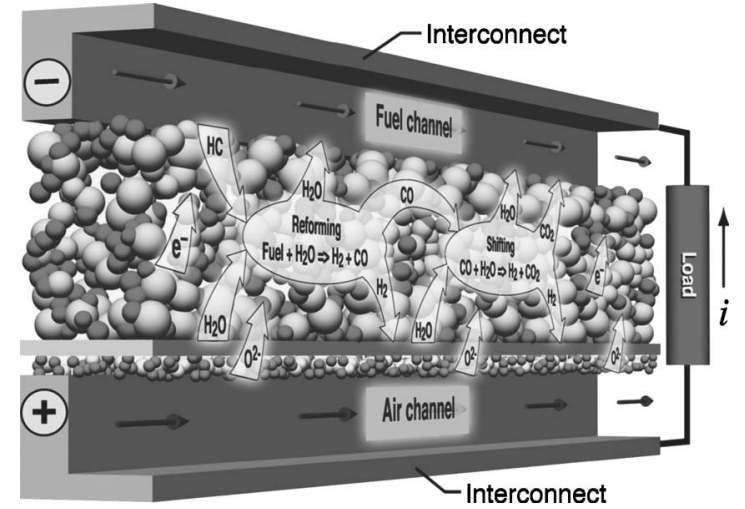

Figure 1. Cutaway view of an anode-supported solid-oxide fuel cell section, showing some possible heterogeneous reaction processes.

particles. In principle, the porosity, particle, and pore sizes, and chemical composition of the anode may all vary through the thickness (i.e., functional grading).

On the cathode side, oxygen from the air is reduced electrocatalytically to draw electrons from the cathode and to produce the oxygen ions that enter the dense electrolyte, and flow across it to replenish the ions lost on the anode side.

Along the length of the fuel channel, the fuel stream becomes increasingly diluted with reaction products (i.e., $\mathrm{H}_{2} \mathrm{O}$ and $\mathrm{CO}_{2}$ ), and depleted in fuel. The air channel also becomes depleted in oxygen (although it is typical to operate cells with an oversupply of air so that the relative increase in the $\mathrm{N}_{2}$ fraction is usually a small effect). As a result, the difference in oxygen ion electrochemical potential across the electrolyte drops, reducing the ability to extract further electrical power. This drop in the thermodynamic driving force, along with variation in various internal losses (overpotentials) along the length of a channel results in the local current density varying along the length of the channel.

Channel flow.- The gas flow in the fuel and air channels is considered to be one-dimensional and laminar, neglecting variations of the gas composition transverse to the flow direction. This is a good approximation, because fuel and air channels typically have characteristic diameters less than a centimeter and mean velocities of less than $100 \mathrm{~cm} / \mathrm{s}$. Under these circumstances, the Reynolds number is on the order of 100 or less. Consequently, the flow is highly viscous and a fully developed velocity profile is established very near the channel entrance. Rapid diffusion of species across the channel width homogenizes the composition transverse to the flow.

The steady plug-flow model within the channels can be summarized as $^{28-30}$

$$
\begin{gathered}
\frac{d\left(\rho Y_{k} u\right)}{d x}=\frac{P_{\mathrm{e}}}{A_{\mathrm{c}}} J_{k} W_{k} \quad k=1, \ldots, K_{\mathrm{g}} \\
\frac{d(\rho u)}{d x}=\sum_{k=1}^{K_{g}} \frac{P_{e}}{A_{c}} J_{k} W_{k}
\end{gathered}
$$

The independent variable is distance along the channel $x$, and the dependent variables are mean velocity $u$, and $K_{g}$ species mass fractions $Y_{k}$. The local density $\rho$ is determined from a perfect-gas equation of state

$$
\rho=\frac{p}{R T} \frac{1}{\sum Y_{k} / W_{k}}
$$

The species molecular weights are $W_{k}$.

The channel geometry is characterized by the cross-sectional area $A_{c}$, and the perimeter associated with the electrochemically 


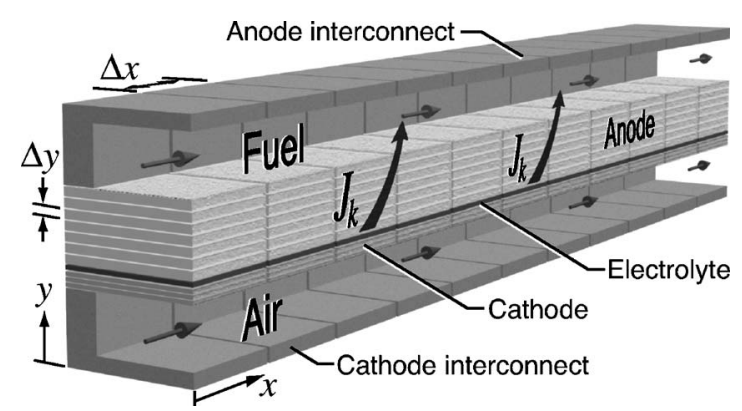

Figure 2. Finite volume representation used for simulation.

active MEA is represented by $P_{e}$. In Fig. $2 P_{e}$ includes the width of the gas channel plus the width of the electrode that lies under the interconnect rib.

As illustrated in Fig. 2, the variables $J_{k}$ are the species mole fluxes that enter (or leave) the flow channels to (or from) the MEA structure. These fluxes depend on the local electric-current density $i(x)$ and heterogeneous chemistry within the porous-electrode structure. The mass-exchange between the MEA and the channels couples the conservation equations for the channel flow and the reacting porous-media flow in the electrodes.

Although species diffusion in the flow direction could be retained in Eq. 4, it is usually negligible under SOFC conditions. Even for light species like hydrogen, the diffusion velocities are around $1 \mathrm{~cm} / \mathrm{s}$, with typical convective velocities on the order of 10 to $100 \mathrm{~cm} / \mathrm{s}$.

The model could also incorporate gas-phase chemistry within the channels. Especially for light hydrocarbons, the elementary homogeneous chemistry is relatively well understood. However, with methane as a fuel and residence times of a few seconds, there is relatively little homogeneous reaction below around $800{ }^{\circ} \mathrm{C} .{ }^{31}$ However, for higher temperatures or for higher hydrocarbon fuels, homogeneous chemistry can play a substantially larger role. When considering the formation of polyaromatic deposits, homogeneous reaction plays a large role. ${ }^{32,33}$ Gas-phase chemistry may also play an important role under partial-oxidation conditions where oxygen is mixed with the fuel. Beyond the need for a reaction mechanism and increasing the problem size, including homogeneous chemistry adds no essential complications to the modeling or the solution algorithm.

The system can be extended to include momentum and energy equations that are solved to predict pressure and temperature profiles. The boundary conditions depend on system-wide considerations, such as position in the stack, interconnect materials, external insulation, etc. In this paper, which is particularly concerned with the incorporation of detailed chemistry and considers a single set of channels, the pressure and temperature are assumed to be uniform.

Porous electrodes. - Within the porous electrodes, the steadystate fluxes of each species satisfy

$$
\nabla \cdot \mathbf{J}_{k}=A_{s} \dot{s}_{\text {gas }, k}, \quad k=1, \ldots, K_{g}
$$

where $\mathbf{J}_{k}$ is the net molar flux vector for gaseous species $k, \dot{s}_{\text {gas }, k}$ is its net production rate due to heterogeneous chemistry, and $A_{s}$ is the active catalyst area per unit volume.

The molar fluxes are evaluated using the dusty gas model (DGM), in which the fluxes are driven by gradients in concentrations and pressure. ${ }^{34}$ Because the electrode thickness is much smaller than its length, the gradients are primarily in the $y$ direction, and therefore the transport through the electrode is approximately one-dimensional. In this case, Eq. 7 may be simplified to

$$
\frac{d J_{k, y}}{d y}=A_{s} \dot{s}_{\text {gas }, k} \quad k=1, \ldots, K_{g}
$$

The molar production rates are evaluated using a heterogeneous reaction mechanism (e.g., Table I). Since this mechanism is formu- lated in terms of elementary reactions on the catalyst surface, the reaction rates depend both on the concentrations of the gaseous reactants and on the coverages of the surface species representing reactive surface sites and adsorbates. Since these coverages are not known a priori, they must be determined as part of the solution.

Unlike the gaseous species, the surface species are effectively immobile on length scales larger than an individual catalyst particle. Therefore, at steady state, the surface coverages must take on values such that the net production rate due to chemistry is zero for every surface species

$$
\dot{s}_{\text {surf }, k}=0, \quad k=1, \ldots, K_{\mathrm{s}}
$$

Here, $K_{s}$ is the total number of surface species. by

The net production rate of any species (gas or surface) is given

$$
\dot{s}_{k}=\sum_{i} v_{k i} q_{i}
$$

where $q_{i}$ is the rate of reaction $i$ and $v_{k i}$ is the net stoichiometric coefficient of the species in question in reaction $i$ (positive for products, negative for reactants). The reaction rates $q_{i}$ are computed assuming mass-action kinetics, ${ }^{30}$ with temperature-dependent rate coefficients in Arrhenius form $k_{i}=A_{i} T^{n} \exp \left(-E_{i} / R T\right)$. As discussed below, for some reactions the activation energy is allowed to depend on species coverages.

The dusty gas model. - The fluxes $J_{k}$ are computed using the dusty gas model, ${ }^{34}$ which is a multicomponent transport model derived from kinetic theory to describe the transport of a gas mixture through a porous matrix consisting of stationary and uniformly distributed particles. It may be used over the full range of Knudsen number, from values much larger than 1 (molecule-wall collisions dominate), to values much less than 1 (molecule-molecule collisions dominate), and also includes the flow induced by a pressure gradient (Darcy flow).

The DGM can be written as an implicit relationship among the molar concentrations, molar fluxes, concentrations gradients, and the pressure gradient ${ }^{35,36}$

$$
\sum_{\ell \neq k} \frac{\left[X_{\ell}\right] \mathbf{J}_{k}-\left[X_{k}\right] \mathbf{J}_{\ell}}{\left[X_{T}\right] D_{k \ell}^{e}}+\frac{\mathbf{J}_{k}}{D_{k, \mathrm{Kn}}^{e}}=-\boldsymbol{\nabla}\left[X_{k}\right]-\frac{\left[X_{k}\right]}{D_{k, \mathrm{Kn}}^{e}} \frac{B_{g}}{\mu} \boldsymbol{\nabla} p
$$

In this relationship $\mathbf{J}_{k}$ is the molar flux of gas-phase species $k$, $\left[X_{k}\right]$ are the molar concentrations, and $\left[X_{T}\right]=p / R T$ is the total molar concentration. The mixture viscosity is given as $\mu$, and $D_{k \ell}^{e}$ and $D_{k, \mathrm{Kn}}^{e}$ are the effective molecular binary diffusion coefficients and Knudsen diffusion coefficients. The permeability of the porous network is given as $B_{g}$.

The effective molecular binary diffusion coefficients in the porous media $D_{k \ell}^{e}$ are related to the ordinary binary diffusion coefficients $D_{k \ell}$ in the gas phase as

$$
D_{k \ell}^{e}=\frac{\phi_{g}}{\tau_{g}} D_{k \ell}
$$

The porous media porosity is given as $\phi_{g}$ and the tortuousity is given as $\tau_{g}$. The ordinary binary diffusion coefficients $D_{k \ell}$ and the viscosity $\mu$ may be determined from standard expressions derived from kinetic theory. ${ }^{30}$ Software packages that compute these are also available. ${ }^{37,38}$

Knudsen diffusion, which occurs due to gas-wall collisions, becomes dominant when the mean-free path of the molecular species is much larger than the pore diameter. The effective Knudsen diffusion coefficient can be expressed as

$$
D_{k, \mathrm{Kn}}^{e}=\frac{4}{3} \frac{\phi_{g}}{\tau_{g}} r_{p} \sqrt{\frac{8 R T}{\pi W_{k}}}
$$

where $r_{p}$ is the average pore radius. 
Table I. Heterogeneous reaction mechanism for $\mathrm{CH}_{4}$ reforming on Ni-based catalysts.

\begin{tabular}{|c|c|c|c|c|}
\hline & Reaction & $A^{\mathrm{a}}$ & $n$ & $E^{\mathrm{a}}$ \\
\hline 1 & $\mathrm{H}_{2}+(\mathrm{Ni})+(\mathrm{Ni}) \rightarrow \mathrm{H}(\mathrm{Ni})+\mathrm{H}(\mathrm{Ni})$ & $1.000 \cdot 10^{-02 b}$ & 0.0 & 0.00 \\
\hline 2 & $\mathrm{H}(\mathrm{Ni})+\mathrm{H}(\mathrm{Ni}) \rightarrow(\mathrm{Ni})+(\mathrm{Ni})+\mathrm{H}_{2}$ & $5.593 \cdot 10^{+19}$ & 0.0 & 88.12 \\
\hline 3 & $\mathrm{O}_{2}+(\mathrm{Ni})+(\mathrm{Ni}) \rightarrow \mathrm{O}(\mathrm{Ni})+\mathrm{O}(\mathrm{Ni})$ & $1.000 \cdot 10^{-02 b}$ & 0.0 & 0.00 \\
\hline 4 & $\mathrm{O}(\mathrm{Ni})+\mathrm{O}(\mathrm{Ni}) \rightarrow(\mathrm{Ni})+(\mathrm{Ni})+\mathrm{O}_{2}$ & $2.508 \cdot 10^{+23}$ & 0.0 & 470.39 \\
\hline 5 & $\mathrm{CH}_{4}+(\mathrm{Ni}) \rightarrow \mathrm{CH}_{4}(\mathrm{Ni})$ & $8.000 \cdot 10^{-03 b}$ & 0.0 & 0.00 \\
\hline 6 & $\mathrm{CH}_{4}(\mathrm{Ni}) \rightarrow(\mathrm{Ni})+\mathrm{CH}_{4}$ & $5.302 \cdot 10^{+15}$ & 0.0 & 33.15 \\
\hline 7 & $\mathrm{H}_{2} \mathrm{O}+(\mathrm{Ni}) \rightarrow \mathrm{H}_{2} \mathrm{O}(\mathrm{Ni})$ & $1.000 \cdot 10^{-01 \mathrm{~b}}$ & 0.0 & 0.00 \\
\hline 8 & $\mathrm{H}_{2} \mathrm{O}(\mathrm{Ni}) \rightarrow(\mathrm{Ni})+\mathrm{H}_{2} \mathrm{O}$ & $4.579 \cdot 10^{+12}$ & 0.0 & 62.68 \\
\hline 9 & $\mathrm{CO}_{2}+(\mathrm{Ni}) \rightarrow \mathrm{CO}_{2}(\mathrm{Ni})$ & $1.000 \cdot 10^{-05 b}$ & 0.0 & 0.00 \\
\hline 10 & $\mathrm{CO}_{2}(\mathrm{Ni}) \rightarrow(\mathrm{Ni})+\mathrm{CO}_{2}$ & $9.334 \cdot 10^{+07}$ & 0.0 & 28.80 \\
\hline 11 & $\mathrm{CO}+(\mathrm{Ni}) \rightarrow \mathrm{CO}(\mathrm{Ni})$ & $5.000 \cdot 10^{-01 \mathrm{~b}}$ & 0.0 & 0.00 \\
\hline \multirow[t]{2}{*}{12} & $\mathrm{CO}(\mathrm{Ni}) \rightarrow(\mathrm{Ni})+\mathrm{CO}$ & $4.041 \cdot 10^{+11}$ & 0.0 & 112.85 \\
\hline & & $\epsilon_{\mathrm{CO}(\mathrm{s})}$ & & $-50.0^{c}$ \\
\hline 13 & $\mathrm{O}(\mathrm{Ni})+\mathrm{H}(\mathrm{Ni}) \rightarrow \mathrm{OH}(\mathrm{Ni})+(\mathrm{Ni})$ & $5.000 \cdot 10^{+22}$ & 0.0 & 97.90 \\
\hline 14 & $\mathrm{OH}(\mathrm{Ni})+(\mathrm{Ni}) \rightarrow \mathrm{O}(\mathrm{Ni})+\mathrm{H}(\mathrm{Ni})$ & $2.005 \cdot 10^{+21}$ & 0.0 & 37.19 \\
\hline 15 & $\mathrm{OH}(\mathrm{Ni})+\mathrm{H}(\mathrm{Ni}) \rightarrow \mathrm{H}_{2} \mathrm{O}(\mathrm{Ni})+(\mathrm{Ni})$ & $3.000 \cdot 10^{+20}$ & 0.0 & 42.70 \\
\hline 16 & $\mathrm{H}_{2} \mathrm{O}(\mathrm{Ni})+(\mathrm{Ni}) \rightarrow \mathrm{OH}(\mathrm{Ni})+\mathrm{H}(\mathrm{Ni})$ & $2.175 \cdot 10^{+21}$ & 0.0 & 91.36 \\
\hline 17 & $\mathrm{OH}(\mathrm{Ni})+\mathrm{OH}(\mathrm{Ni}) \rightarrow \mathrm{O}(\mathrm{Ni})+\mathrm{H}_{2} \mathrm{O}(\mathrm{Ni})$ & $3.000 \cdot 10^{+21}$ & 0.0 & 100.00 \\
\hline 18 & $\mathrm{O}(\mathrm{Ni})+\mathrm{H}_{2} \mathrm{O}(\mathrm{Ni}) \rightarrow \mathrm{OH}(\mathrm{Ni})+\mathrm{OH}(\mathrm{Ni})$ & $5.423 \cdot 10^{+23}$ & 0.0 & 209.37 \\
\hline 19 & $\mathrm{O}(\mathrm{Ni})+\mathrm{C}(\mathrm{Ni}) \rightarrow \mathrm{CO}(\mathrm{Ni})+(\mathrm{Ni})$ & $5.200 \cdot 10^{+23}$ & 0.0 & 148.10 \\
\hline \multirow[t]{2}{*}{20} & $\mathrm{CO}(\mathrm{Ni})+(\mathrm{Ni}) \rightarrow \mathrm{O}(\mathrm{Ni})+\mathrm{C}(\mathrm{Ni})$ & $1.418 \cdot 10^{+22}$ & -3.0 & 115.97 \\
\hline & & $\epsilon_{\mathrm{CO}(\mathrm{s})}$ & & $-50.0^{\mathrm{c}}$ \\
\hline \multirow[t]{2}{*}{21} & $\mathrm{O}(\mathrm{Ni})+\mathrm{CO}(\mathrm{Ni}) \rightarrow \mathrm{CO}_{2}(\mathrm{Ni})+(\mathrm{Ni})$ & $2.000 \cdot 10^{+19}$ & 0.0 & 123.60 \\
\hline & & $\epsilon_{\mathrm{CO}(\mathrm{s})}$ & & $-50.0^{\mathrm{c}}$ \\
\hline 22 & $\mathrm{CO}_{2}(\mathrm{Ni})+(\mathrm{Ni}) \rightarrow \mathrm{O}(\mathrm{Ni})+\mathrm{CO}(\mathrm{Ni})$ & $3.214 \cdot 10^{+23}$ & -1.0 & 86.50 \\
\hline \multirow[t]{2}{*}{23} & $\mathrm{HCO}(\mathrm{Ni})+(\mathrm{Ni}) \rightarrow \mathrm{CO}(\mathrm{Ni})+\mathrm{H}(\mathrm{Ni})$ & $3.700 \cdot 10^{+21}$ & 0.0 & 0.0 \\
\hline & & $\epsilon_{\mathrm{CO}(\mathrm{s})}$ & & $50.0^{\mathrm{c}}$ \\
\hline 24 & $\mathrm{CO}(\mathrm{Ni})+\mathrm{H}(\mathrm{Ni}) \rightarrow \mathrm{HCO}(\mathrm{Ni})+(\mathrm{Ni})$ & $2.338 \cdot 10^{+20}$ & -1.0 & 127.98 \\
\hline 25 & $\mathrm{HCO}(\mathrm{Ni})+(\mathrm{Ni}) \rightarrow \mathrm{O}(\mathrm{Ni})+\mathrm{CH}(\mathrm{Ni})$ & $3.700 \cdot 10^{+24}$ & -3.0 & 95.80 \\
\hline 26 & $\mathrm{O}(\mathrm{Ni})+\mathrm{CH}(\mathrm{Ni}) \rightarrow \mathrm{HCO}(\mathrm{Ni})+(\mathrm{Ni})$ & $7.914 \cdot 10^{+20}$ & 0.0 & 114.22 \\
\hline 27 & $\mathrm{CH}_{4}(\mathrm{Ni})+(\mathrm{Ni}) \rightarrow \mathrm{CH}_{3}(\mathrm{Ni})+\mathrm{H}(\mathrm{Ni})$ & $3.700 \cdot 10^{+21}$ & 0.0 & 57.70 \\
\hline 28 & $\mathrm{CH}_{3}(\mathrm{Ni})+\mathrm{H}(\mathrm{Ni}) \rightarrow \mathrm{CH}_{4}(\mathrm{Ni})+(\mathrm{Ni})$ & $4.438 \cdot 10^{+21}$ & 0.0 & 58.83 \\
\hline 29 & $\mathrm{CH}_{3}(\mathrm{Ni})+(\mathrm{Ni}) \rightarrow \mathrm{CH}_{2}(\mathrm{Ni})+\mathrm{H}(\mathrm{Ni})$ & $3.700 \cdot 10^{+24}$ & 0.0 & 100.00 \\
\hline 30 & $\mathrm{CH}_{2}(\mathrm{Ni})+\mathrm{H}(\mathrm{Ni}) \rightarrow \mathrm{CH}_{3}(\mathrm{Ni})+(\mathrm{Ni})$ & $9.513 \cdot 10^{+22}$ & 0.0 & 52.58 \\
\hline 31 & $\mathrm{CH}_{2}(\mathrm{Ni})+(\mathrm{Ni}) \rightarrow \mathrm{CH}(\mathrm{Ni})+\mathrm{H}(\mathrm{Ni})$ & $3.700 \cdot 10^{+24}$ & 0.0 & 97.10 \\
\hline 32 & $\mathrm{CH}(\mathrm{Ni})+\mathrm{H}(\mathrm{Ni}) \rightarrow \mathrm{CH}_{2}(\mathrm{Ni})+(\mathrm{Ni})$ & $3.008 \cdot 10^{+24}$ & 0.0 & 76.43 \\
\hline 33 & $\mathrm{CH}(\mathrm{Ni})+(\mathrm{Ni}) \rightarrow \mathrm{C}(\mathrm{Ni})+\mathrm{H}(\mathrm{Ni})$ & $3.700 \cdot 10^{+21}$ & 0.0 & 18.80 \\
\hline 34 & $\mathrm{C}(\mathrm{Ni})+\mathrm{H}(\mathrm{Ni}) \rightarrow \mathrm{CH}(\mathrm{Ni})+(\mathrm{Ni})$ & $4.400 \cdot 10^{+22}$ & 0.0 & 160.49 \\
\hline 35 & $\mathrm{O}(\mathrm{Ni})+\mathrm{CH}_{4}(\mathrm{Ni}) \rightarrow \mathrm{CH}_{3}(\mathrm{Ni})+\mathrm{OH}(\mathrm{Ni})$ & $1.700 \cdot 10^{+24}$ & 0.0 & 88.30 \\
\hline 36 & $\mathrm{CH}_{3}(\mathrm{Ni})+\mathrm{OH}(\mathrm{Ni}) \rightarrow \mathrm{O}(\mathrm{Ni})+\mathrm{CH}_{4}(\mathrm{Ni})$ & $8.178 \cdot 10^{+22}$ & 0.0 & 28.72 \\
\hline 37 & $\mathrm{O}(\mathrm{Ni})+\mathrm{CH}_{3}(\mathrm{Ni}) \rightarrow \mathrm{CH}_{2}(\mathrm{Ni})+\mathrm{OH}(\mathrm{Ni})$ & $3.700 \cdot 10^{+24}$ & 0.0 & 130.10 \\
\hline 38 & $\mathrm{CH}_{2}(\mathrm{Ni})+\mathrm{OH}(\mathrm{Ni}) \rightarrow \mathrm{O}(\mathrm{Ni})+\mathrm{CH}_{3}(\mathrm{Ni})$ & $3.815 \cdot 10^{+21}$ & 0.0 & 21.97 \\
\hline 39 & $\mathrm{O}(\mathrm{Ni})+\mathrm{CH}_{2}(\mathrm{Ni}) \rightarrow \mathrm{CH}(\mathrm{Ni})+\mathrm{OH}(\mathrm{Ni})$ & $3.700 \cdot 10^{+24}$ & 0.0 & 126.80 \\
\hline 40 & $\mathrm{CH}(\mathrm{Ni})+\mathrm{OH}(\mathrm{Ni}) \rightarrow \mathrm{O}(\mathrm{Ni})+\mathrm{CH}_{2}(\mathrm{Ni})$ & $1.206 \cdot 10^{+23}$ & 0.0 & 45.42 \\
\hline 41 & $\mathrm{O}(\mathrm{Ni})+\mathrm{CH}(\mathrm{Ni}) \rightarrow \mathrm{C}(\mathrm{Ni})+\mathrm{OH}(\mathrm{Ni})$ & $3.700 \cdot 10^{+21}$ & 0.0 & 48.10 \\
\hline 42 & $\mathrm{C}(\mathrm{Ni})+\mathrm{OH}(\mathrm{Ni}) \rightarrow \mathrm{O}(\mathrm{Ni})+\mathrm{CH}(\mathrm{Ni})$ & $1.764 \cdot 10^{+21}$ & 0.0 & 129.08 \\
\hline
\end{tabular}

${ }^{\mathrm{a}}$ Arrhenius parameters for the rate constants written in the form: $k=A T^{n} \exp (-E / R T)$. The units of $A$ are given in terms of moles, centimeters, and seconds. $E$ is in $\mathrm{kJ} / \mathrm{mol}$.

${ }^{\mathrm{b}}$ Sticking coefficient.

${ }^{c}$ Coverage-dependent activation energy (see Eq. 30). Total available surface site density is $\Gamma=2.60 \times 10^{-9} \mathrm{~mol} / \mathrm{cm}^{2}$.

For the case when the porous electrode is formed by closely packed spherical particles with diameter $d_{p}$ (certainly an idealization), the permeability can be expressed by the Kozeny-Carman relationship ${ }^{39}$ as

$$
B_{g}=\frac{\phi_{g}^{3} d_{p}^{2}}{72 \tau_{g}\left(1-\phi_{g}\right)^{2}}
$$

Other porous-media situations have different permeability relationships, often empirical.

Equation 11 is a system of equations that must be solved simultaneously for each of the $k$ components of $\mathbf{J}_{k}$. However, it can be inverted to develop a direct representation of $\mathbf{J}_{k}$ as

$$
\mathbf{J}_{k}=-\sum_{\ell=1}^{K_{g}} D_{k \ell}^{\mathrm{DGM}} \nabla\left[X_{\ell}\right]-\left(\sum_{\ell=1}^{K_{g}} D_{k \ell}^{\mathrm{DGM}} \frac{\left[X_{\ell}\right]}{D_{\ell, \mathrm{Kn}}^{e}}\right) \frac{B_{g}}{\mu} \nabla p
$$

where $D_{k \ell}^{\text {DGM }}$ are defined as DGM diffusion coefficients. The DGM diffusion coefficients can be represented as a matrix inverse

$$
D_{k \ell}^{\mathrm{DGM}}=H^{-1}
$$

where the elements of the $H$ matrix are 


$$
h_{k \ell}=\left[\frac{1}{D_{k, \mathrm{Kn}}^{e}}+\sum_{j \neq k} \frac{X_{j}}{D_{k j}^{e}}\right] \delta_{k \ell}+\left(\delta_{k \ell}-1\right) \frac{X_{k}}{D_{k \ell}^{e}}
$$

In this expression $X_{k}$ are mole fractions and $\delta_{i j}$ is the Kronecker delta.

Interface conditions. - When the DGM expressions for the fluxes are substituted into Eq. 8, it takes the form of a second-order boundary-value problem. Its solution requires boundary conditions at the channel and dense-electrolyte interfaces. At the electrodechannel interface, the gas-phase species composition is required to match that in the gas channel. At the electrode-electrolyte interface, the boundary condition is set by the electrochemical change-transfer reactions at the electrode-electrolyte triple-phase boundary (TPB) regions as

$$
\mathbf{j}_{k} \cdot \mathbf{n}=W_{k} v_{k} \frac{i}{n_{e} F}
$$

where $\mathbf{n}$ is the unit normal vector at the electrode-electrolyte interface, $F$ is the Faraday constant, $v_{k}$ is the stoichiometric coefficient for species $k$ in the charge-transfer reaction, $n_{e}$ is the number of electrons transferred, and $i$ is the current density. For charge transfer via a global hydrogen reaction (i.e., $\mathrm{H}_{2}+\mathrm{O}^{2-} \rightarrow \mathrm{H}_{2} \mathrm{O}+2 \mathrm{e}^{-}$), $\nu_{\mathrm{H}_{2}}=-1, \nu_{\mathrm{H}_{2} \mathrm{O}}=1$, and $n_{e}=2$.

The current density $i$ is also an unknown that must be determined as part of the solution. As discussed below, the current density is determined from charge-transfer reactions that may be represented in a modified Butler-Volmer form.

Electrochemistry.-Charge-transfer processes are surely among the least well-understood aspects of fuel-cell chemistry. Ultimately, our objective is to describe charge-transfer kinetics entirely in terms of elementary reaction steps, in a manner that parallels the treatment of thermal heterogeneous chemistry. In the models described here, however, we retain a Butler-Volmer formalism for the chargetransfer steps, although one that is informed by the consideration of elementary steps. This approach provides quantitative information about important functional dependencies such as the reaction orders in the exchange current density.

The potential difference $E_{\text {cell }}$ across the cell is given by

$$
\begin{aligned}
E_{\text {cell }} & =\phi_{c}-\phi_{a} \\
& =E_{c}+\left(\phi_{e, c}-\phi_{e, a}\right)-E_{a} \\
& =E_{c}-E_{a}-\eta_{\mathrm{ohm}}(i)
\end{aligned}
$$

Here, $\phi_{i}$ and $\phi_{e, i}$ are the electrode potential and the potential within the electrolyte just outside the space charge region at the electrode interface, respectively, and $E_{i}=\phi_{i}-\phi_{e, i}$. The term $\eta_{\mathrm{ohm}}(i)$ is the ohmic overpotential $\phi_{e, a}-\phi_{e, c}$.

To use Eq. 21 to compute $E_{\text {cell }}(i)$, it would be necessary to supply additional equations to compute $E_{c}$ and $E_{a}$. While this can be done by writing equations to describe charging of the double layer at each interface, ${ }^{26}$ here we take a simpler approach.

For an ideal reversible cell exposed to the same gas environment as the actual cell, this expression becomes

$$
E_{\text {rev }}=E_{c, \text { rev }}-E_{a, \text { rev }}
$$

Subtracting Eq. 22 from Eq. 21 and introducing the activation overpotential $\eta_{\text {act }}=E-E_{\text {rev }}$, Eq. 21 may be written in the form

$$
E_{\text {cell }}=E_{\text {rev }}-\eta_{\text {act }, a}(i)-\eta_{\text {ohm }}(i)-\left|\eta_{\text {act }, c}(i)\right|
$$

If the gas compositions at the triple-phase regions of each electrode are locally in chemical equilibrium, then the reversible potential is well-defined, and may be computed by applying the Nernst equation to any desired global oxidation reaction. The simplest form in this case is $E_{\mathrm{rev}}=-(R T / 4 F) \ln \left(P_{\mathrm{O}_{2}, c} / P_{\mathrm{O}_{2}, a}\right)$. The equilibrium assumption will generally be very good on the cathode side, but may not hold on the anode side if residual hydrocarbons are still present in the gas in the triple-phase regions. If the anode-side gas composition is not locally in equilibrium, then the oxidation reaction for each fuel species would result in a different cell potential; to compute $E_{\text {rev }}$ in this case, something must be known about which species are electrochemically active. Here, we assume that the hydrogen electro-oxidation pathway is dominant, and so the reversible cell potential may be computed using the Nernst equation for the hydrogen oxidation reaction

$$
E_{\mathrm{rev}}=E^{\mathrm{o}}+\frac{R T}{2 F} \ln \left(\frac{p_{\mathrm{H}_{2}, a}}{p_{\mathrm{H}_{2} \mathrm{O}, a}}\right)+\frac{R T}{2 F} \ln \left(p_{\mathrm{O}_{2}, c}^{1 / 2}\right)
$$

where

$$
E^{\mathrm{o}}=\frac{1}{2 F}\left(\mu_{\mathrm{H}_{2}}^{\mathrm{o}}+\frac{1}{2} \mu_{\mathrm{O}_{2}}^{\mathrm{o}}-\mu_{\mathrm{H}_{2} \mathrm{O}}^{\mathrm{o}}\right)
$$

is the ideal standard potential and $\mu_{k}^{o}$ are standard-state chemical potentials. As indicated by the subscripts $a$ and $c$, the gas-phase species partial pressures (measured in atmospheres) in Eq. 24 are evaluated at the anode and cathode interfaces with the dense electrolyte.

We assume that the interconnect material has very low electrical resistance, so that $E_{\text {cell }}$ is uniform down the channel. The reversible potential $E_{\text {rev }}(x)$, however, varies along the channel length as the fuel is depleted and diluted.

Since the full reactive-transport problem within the electrodes is solved in this model, there is no need for the explicit evaluation or consideration of concentration overpotentials. Rather, the gas-phase compositions needed to evaluate the reversible potential are evaluated at the interface between the porous electrode and the dense electrolyte.

The charge-transfer activation overpotentials $\left(\eta_{\text {act, } a}\right.$ and $\left.\eta_{\text {act, }, c}\right)$ at the electrode-electrolyte interfaces are calculated by inverting Butler-Volmer equations to determine overpotentials as a function of current density. The particular forms of the Butler-Volmer equations are discussed in the following section and the Appendix.

The ohmic overpotential $\eta_{\mathrm{ohm}}$, due primarily to resistance of ion transport in the electrolyte, can be represented as

$$
\eta_{\text {ohm }}=i R_{\text {tot }}
$$

where $R_{\mathrm{tot}}$ is the total area-specific cell resistance, including the solid electrolyte $R_{\mathrm{el}}$ and area-specific resistances in the electrodes $R_{\text {ed }}$. In cermet electrodes with high metal loading, the electrode resistance $R_{\text {ed }}$ is usually negligible. However, in ceramic electrodes (e.g., an LSM cathode) electrode ohmic resistance can be important. The electrolyte resistance can be determined from the ionic conductivity of the electrolyte $\sigma_{\mathrm{el}}$ as $R_{\mathrm{el}}=L_{\mathrm{el}} / \sigma_{\mathrm{el}}$, where $L_{\mathrm{el}}$ is the electrolyte thickness. The ionic conductivity of the electrolyte is expressed as

$$
\sigma_{\mathrm{el}}=\sigma_{0} T^{-1} \exp \left(-\frac{E_{\mathrm{el}}}{R T}\right)
$$

where $E_{\mathrm{el}}$ is the activation energy for ion transport.

Once the current density $i(x)$ is determined, the molar flux of the gas species from the electrochemical reactions in the MEA structure can be evaluated as $J_{\mathrm{H}_{2}, a}=-i / 2 F$ and $J_{\mathrm{H}_{2} \mathrm{O}, a}=i / 2 F$ for $\mathrm{H}_{2}$ electrochemical oxidation at the anode, and $J_{\mathrm{O}_{2}, c}=i / 4 F$ for the $\mathrm{O}_{2}$ electrochemical reduction at the cathode. A positive flux at the anode means that mass enters the anode pore space from the anodeelectrolyte three-phase boundaries. A positive flux at the cathode means that mass leaves the cathode pore space and enters the electrolyte membrane.

\section{Numerical Solution Procedure}

Equations 4, 5, 8, 9, 15, and 23 form a coupled nonlinear system of equations to compute the velocity $u$ and mass fractions $Y_{k}\left(k=1, \ldots, K_{g}\right)$ along the channels; gas-phase mass fractions $Y_{k}\left(k=1, \ldots, K_{g}\right)$ and surface coverages $\theta_{k}\left(k=1, \ldots, K_{s}\right)$ within the electrodes, and the electric current density $i$. Mathematically the 
equations form a differential-algebraic system, which can be solved numerically. ${ }^{40}$ To solve these equations, they are first cast in finitevolume form.

The gas channels are divided into cells of equal width $\Delta x$. Because the gas flow in the channels is approximated as a plug flow (i.e., no variations transverse to the flow direction), there is no need to subdivide the gas channel cells vertically. The electrodes are partitioned into cells of width $\Delta x$ and height $\Delta y$. Since the channel length is much longer than the thickness of either electrode, $\Delta y$ $\ll \Delta x$. The electrodes are approximated as continuous media, with homogenized, volume-averaged properties. The gradients through the thickness of the porous electrodes $\left(\nabla\left[X_{k}\right]\right.$ and $\left.\nabla p\right)$ that are needed to evaluate the dusty-gas mass fluxes crossing cell boundaries are replaced by finite-difference approximations using the solution values at cell centers.

Overall, the numerical approach takes the form of a marching algorithm, beginning from the channel inlet and marching in $x$ toward the channel exit. Because of strong coupling and potentially stiff chemistry through the thickness of the MEA ( $y$ direction as shown in Fig. 2), an implicit algorithm is used. At each axial position $x$ along the channel, the dependent-variable vector is ordered as

$$
\boldsymbol{\Phi}=\left[(\mathbf{Y}, u)_{a},(\mathbf{Y}, \boldsymbol{\theta})_{a, 1}, \ldots,(\mathbf{Y}, \boldsymbol{\theta})_{a, M}, i,(\mathbf{Y}, \boldsymbol{\theta})_{c, 1}, \ldots,(\mathbf{Y}, \boldsymbol{\theta})_{c, N},(\mathbf{Y}, u)_{c}\right]
$$

The variable ordering is arranged so that the Jacobian matrix used in a Newton algorithm has a banded structure. This vector begins with gas-phase variables in the anode channel (density, mass fractions, and velocity), followed by the porous-anode variables (gas-phase density, mass fractions, and surface coverages), the current density $i$. On the cathode side the porous-media variables are followed by the cathode-channel gas-phase variables. The porous anode is differenced into $M$ finite volumes and the porous cathode is divided into $N$ finite volumes. On the anode side the length of the gas-phase mass-fraction vector $\mathbf{Y}$ is $K_{g, a}$, and on the cathode side the massfraction vector is length $K_{g, c}$. Similarly, the surface species and coverages are different on the anode and cathode sides. The vectors of surface coverages $\boldsymbol{\theta}$ have lengths $K_{s, a}$ and $K_{s, c}$.

The spatially varying activation overpotentials $\eta_{\text {act }}(i)$ must be determined such that both Eq. 23 and the Butler-Volmer equations are satisfied. As discussed in the following section, the modified Butler-Volmer equations are most naturally written with the current density as a function of activation overpotential (e.g., Eq. 37). The activation overpotentials could be introduced as dependent variables in $\boldsymbol{\Phi}$. However, we often implement the algorithm using an iterative solution of the Butler-Volmer equations to determine $\eta_{\text {act }}(i)$, thus not formally introducing $\eta_{\text {act }}$ as dependent variables.

The system of equations at each axial location $x$ may be written in residual form as

$$
\mathbf{F}(\boldsymbol{\Phi})=0
$$

A hybrid damped-Newton / time-integration method is used to solve Eq. 29. The procedure differs only in a few details from the algorithm described in Kee et al., ${ }^{30}$ and is not described further here.

Convective terms in the gas channel are evaluated using upwind differencing, which means that the conservation equations in the channel at any axial position depend on the solution in the channel (i.e., density, mass fractions, and velocity) at the adjacent upstream mesh interval. The Newton iteration requires an initial estimate for the dependent variable vector $\boldsymbol{\Phi}$. This estimate is taken as the solution vector from the immediate upstream mesh interval. Because the solution changes gradually and smoothly along the length of the channel, the Newton iteration converges rapidly at each $x$ mesh interval.

The model described here is implemented both in $\mathrm{C}++$ using a Cantera $^{38}$ interface and in Fortran using a Chemkin ${ }^{37,41,42}$ interface. This model needs thermodynamic and transport properties for each species. It also needs to evaluate chemical reaction rates using detailed reaction mechanisms. These tasks have been automated in both the Cantera or Chemkin software packages, which provide user-oriented software and needed databases. These packages also provide useful error-checking functions like assuring that reactions balance.

Using a typical discretization on the order of 200 axial cells along the channel and 25 cells through the thickness of the electrodes, a steady-state solution requires a few minutes on a personal computer.

\section{Reaction Mechanisms}

To close the system of equations, it is necessary to specify how the thermal heterogeneous production rates $\dot{s}_{\text {gas }, k}, k=1, \ldots, K_{g}$ and $\dot{s}_{\text {surf }, k}, k=1, \ldots, K_{s}$ are to be computed. Additionally, the chargetransfer pathways and rates must be specified. This includes specifying how exchange current densities depend on gas composition, and establishing values for charge-transfer coefficients.

At the simplest level, the heterogeneous production rates (e.g., reforming) might be computed using experimental correlations that simply express $\dot{s}_{\text {gas }, k}$ for each species as a function of the local gas composition, and do not require consideration of any surface species (i.e., $K_{s}=0$ ). However, most global rate expressions derived directly from experiment do not account for the reverse reactions that become important as the gas composition approaches equilibrium. Consequently, this approach may lead to spurious gas compositions in the fast-chemistry limit, which will lead to errors in the computed reversible potentials.

A much more robust approach is to formulate the problem in terms of a set of reversible heterogeneous reactions, with rates computed using mass-action kinetics, and reverse rates computed in a manner consistent with thermodynamics. The formalism to do this is standard, ${ }^{30}$ and for sake of brevity will not be repeated here. By choosing the reactions and their rates to fit a wide set of experiments, it is possible with this approach to both accurately represent measured rate data under nonequilibrium conditions, and to insure that all forward and reverse rates precisely balance as equilibrium is approached. For this reason, we adopt this reaction-based formulation here.

Similarly, for the electrochemistry, one might use empirical expressions for the dependence of the exchange current density on composition, or expressions derived from an underlying elementary reaction mechanism. Because the Butler-Volmer form guarantees consistency with thermodynamics $(i=0$ when $\eta=0)$, either approach is possible. Here, we take the latter approach.

Heterogeneous chemistry on nickel.- Nickel is the most common anode metal (in Ni-YSZ cermets) and is certainly a costeffective material. Although there are well-known coking issues associated with $\mathrm{Ni}$ in reforming reactors, there is also considerable evidence that SOFCs can use Ni effectively. Certainly Ni is used successfully as a catalyst for hydrocarbon reforming and shifting to produce $\mathrm{H}_{2}$ and $\mathrm{CO}$.

Our objective here is to incorporate a multistep reaction mechanism into a model that predicts fuel-cell performance. The reactions of methane on $\mathrm{Ni}$ have been extensively studied by various techniques over decades. Depending on the actual process (e.g., steam reforming, dry reforming with $\mathrm{CO}_{2}$, total and partial oxidation), different reaction mechanisms and corresponding kinetic models have been proposed. ${ }^{43-47}$ Recently, mechanistic models based on the knowledge of the elementary steps and their energetics have been developed. ${ }^{46,48}$ Although there is certainly more work to be done, it is clear that reaction mechanisms can be established and validated over widely ranging conditions.

The reaction mechanism $(\text { Table } \mathrm{I})^{\mathrm{d}}$ consists of 42 irreversible reactions among 6 gas-phase and 12 additional adsorbed species. Most reaction rates are represented in the Arrhenius form or as a

${ }^{\mathrm{d}}$ This reaction mechanism may be downloaded from http://www.detchem.com/ mechanisms 
sticking coefficient. However, the net activation energies of reactions $12,20,21$, and 23 depend on the $\mathrm{CO}(\mathrm{s})$ coverage $\theta_{\mathrm{CO}(s)}$ in the form

$$
k=A T^{n} \exp \left(-\frac{E}{R T}\right) \exp \left(-\frac{\epsilon_{\mathrm{CO}(s)} \theta_{\mathrm{CO}(s)}}{R T}\right)
$$

Although the reaction mechanism is written as pairs of irreversible reactions, the reverse rate coefficients depend on the forward rate coefficients and the thermodynamics. ${ }^{30}$ The reverse rate coefficients are computed to ensure thermodynamic consistency and an asymptotic approach to an equilibrium state.

The unity bond index-quadratic exponential potential (UBI-QEP) approach is used to determine the heats of adsorption, reaction enthalpies, and activation barriers for most relevant reactions. ${ }^{4-52}$ Specifically, the UBI-QEP method is used to evaluate kinetic parameters for the desorption of $\mathrm{O}_{2}, \mathrm{CH}_{4}, \mathrm{H}_{2} \mathrm{O}, \mathrm{CO}_{2}$ (reactions 4, 6, 8, and $10),{ }^{49} \mathrm{CO}$ formation and decomposition (reactions 19 and 20), ${ }^{51}$ HCO reactions (reactions 23 and 24), ${ }^{49}$ and nonoxidative methane decomposition and formation (reactions 27-34). ${ }^{51}$ Steam and $\mathrm{CO}_{2}$ formation rates (reactions 13-18, 21, and 22), HCO formation (reactions 25 and 26), and oxidative decomposition and formation of $\mathrm{CH}_{4}$ (reactions 35-42) are derived from a theoretical study of dry methane reforming. ${ }^{52}$ The sticking coefficient for hydrogen (reaction 1) is taken from chemisorption studies on $\mathrm{Ni}(111),{ }^{53}$ and the hydrogen-desorption rate (reaction 2) is based on an experimental study on Ni single-crystal surfaces. ${ }^{54}$ Owing to a lack of data on $\mathrm{Ni}$ surfaces, sticking coefficients for oxygen and steam (reactions 3 and 7) are estimated from studies of methane partial oxidation on rhodium. ${ }^{55}$ Sticking coefficients for $\mathrm{CH}_{4}$ and $\mathrm{CO}_{2}$ adsorption (reactions 5 and 9) are derived from experimental studies of methane reforming and oxidation over Ni-coated monoliths. ${ }^{56}$ The data for $\mathrm{CO}$ adsorption/desorption (reactions 11 and 12) are taken from AlSarraf et al. ${ }^{57}$

Elementary reaction mechanisms can be applied more generally than global mechanisms that may be validated only for specific geometric configurations and operating conditions. The mechanism here was initially developed and validated using $\mathrm{Ni}$-coated honeycomb monoliths for the temperature range from 700 to $1300 \mathrm{~K}$. The validation is based on comparing measured product composition with results of two-dimensional reacting-flow simulations for a single channel.

Experimental conditions consider partial oxidation and steam reforming of $\mathrm{CH}_{4}$, including water-gas-shift and methanation processes. ${ }^{56}$ The $\mathrm{CH}_{4} / \mathrm{O}_{2}$ ratio ranged from 1.5 to 2 and steam was incorporated up to a steam/carbon ratio of 4 . The steam/methane mixture, diluted by $75 \mathrm{vol} \%$ argon, is fed into a series of five cordierite honeycomb monoliths, each $15 \mathrm{~mm}$ in diameter, which are located in a ceramic tube within a furnace. The monoliths are $1 \mathrm{~cm}$ long and composed of straight rectangular channels with hydraulic diameters of $1.1 \mathrm{~mm}$. The center monolith is coated with $3 \%$ $\mathrm{Ni}$ (relative to the monolith weight) by wet impregnation. The reactor is isothermal and product composition is analyzed by mass spectrometry.

In the numerical study, the two-dimensional velocity, density, and concentration profiles in a single channel are computed assuming cylindrical symmetry and boundary-layer assumptions, in which the axial diffusion is neglected. ${ }^{58}$ The latter assumption is justified due to the high flow rates; the velocity at the channel entrance is uniform at $5.6 \mathrm{~cm} / \mathrm{s}$. The model incorporates the heterogeneous chemistry in Table I. Thus, the gas-phase composition profiles and the surface coverages are predicted as a function of axial position in the channel. The model results shown in Fig. 3 were computed with the Detchem ${ }^{59,60}$ software.

Figure 3 shows the numerically predicted and experimentally derived methane conversion and $\mathrm{CO}$ selectivity for steam reforming of methane over supported $\mathrm{Ni}$ at a steam/carbon ratio of 3.07, temperatures in the range 750 to $950^{\circ} \mathrm{C}$, and atmospheric pressure. Both conversion and $\mathrm{CO}$ selectivity increase with increasing temperature.

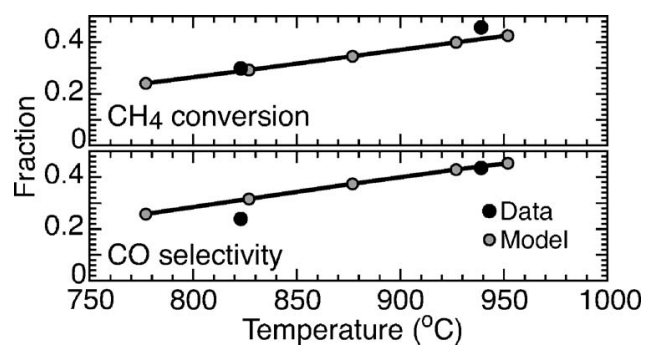

Figure 3. Comparison of measured and predicted methane conversion and $\mathrm{CO}$ selectivity in monolith channels coated with $\mathrm{Ni}$.

In addition to monolith-based validation, we have recently validated this mechanism in specially designed experiments using porous $\mathrm{Ni}$ YSZ anode structures. ${ }^{61}$ These experiments consider both steam and dry reforming of methane.

Because the reaction mechanism is based on elementary molecular processes, it represents all the global processes in an SOFC anode, including (i) steam reforming of $\mathrm{CH}_{4}$ to $\mathrm{CO}$ and $\mathrm{H}_{2}$; (ii) watergas-shift processes; and (iii) surface-carbon coverage. The mechanism includes surface-adsorbed carbon $\mathrm{C}(\mathrm{Ni})$ and oxygen on the surface up to one monolayer $\mathrm{O}(\mathrm{Ni})$. However, the mechanism has not been specifically validated for conditions where coking and bulk-phase Ni oxidation occur. Thus, the examples discussed in this paper use operating conditions where coking and $\mathrm{NiO}$ formation are not primary concerns.

Work remains to be done in the development and validation of elementary heterogeneous reaction mechanisms. For example, elementary mechanisms for carbon-formation and bulk-phase nickel oxidation are particularly needed. Additional experimental data will assist in the further refinement and validation of mechanisms such as the one used here. Moreover, as SOFC technology develops, new materials and material combinations will be used (e.g., copper-ceriabased anodes). As the technology evolves, new reaction mechanisms will be needed. The modeling formalisms described here are capable of handling new or alternative elementary reaction mechanisms in a general way as they are developed, refined, and validated.

Electrochemical oxidation of hydrogen.- In developing an expression for the anode activation overpotential in Butler-Volmer form, it is useful to begin by considering the elementary steps by which hydrogen is electrochemically oxidized. Global electrochemical oxidation of hydrogen can be written in Kröger-Vink notation as

$$
\mathrm{H}_{2}(\mathrm{~g})+\mathrm{O}_{\mathrm{O}}^{\times}(\mathrm{el})=\mathrm{H}_{2} \mathrm{O}(\mathrm{g})+\mathrm{V}_{\mathrm{O}}(\mathrm{el})+2 \mathrm{e}^{-}(\mathrm{a})
$$

which involves species in the gas, electrolyte, and anode (metal) phases. There is considerable debate about the elementary pathways and rate-limiting step. ${ }^{18,19,62-69}$

In this work we begin with a mechanism that includes five elementary reactions in Ni-YSZ three-phase region. The mechanism is similar to the one used by De Boer. ${ }^{1,26,62}$ They are

1. Adsorption/desorption on the Ni surface

$$
\mathrm{H}_{2}(\mathrm{~g})+2(\mathrm{Ni}) \rightleftharpoons 2 \mathrm{H}(\mathrm{Ni})
$$

2. Charge-transfer reactions at the TPB region

$$
\begin{aligned}
& \mathrm{H}(\mathrm{Ni})+\mathrm{O}^{2-}(\mathrm{YSZ}) \rightleftharpoons(\mathrm{Ni})+\mathrm{OH}^{-}(\mathrm{YSZ})+\mathrm{e}^{-}(\mathrm{Ni}) \\
& \mathrm{H}(\mathrm{Ni})+\mathrm{OH}^{-}(\mathrm{YSZ}) \rightleftharpoons(\mathrm{Ni})+\mathrm{H}_{2} \mathrm{O}(\mathrm{YSZ})+\mathrm{e}^{-}(\mathrm{Ni})
\end{aligned}
$$

3. Adsorption/desorption on the YSZ surface

$$
\mathrm{H}_{2} \mathrm{O}(\mathrm{YSZ}) \rightleftharpoons \mathrm{H}_{2} \mathrm{O}(\mathrm{g})+(\mathrm{YSZ})
$$

4. Transfer of oxygen ions between the surface and the bulk YSZ 


$$
\mathrm{O}_{\mathrm{O}}^{\times}(\mathrm{YSZ})+(\mathrm{YSZ}) \rightleftharpoons \mathrm{O}^{2-}(\mathrm{YSZ})+\mathrm{V}_{\mathrm{O}}^{*}(\mathrm{YSZ})
$$

On the $\mathrm{Ni}$ anode surface, $\mathrm{H}(\mathrm{Ni})$ is an adsorbed atomic hydrogen, (Ni) is an empty surface site, and $\mathrm{e}^{-}(\mathrm{Ni})$ is an electron within the $\mathrm{Ni}$ anode. Within the YSZ electrolyte, $\mathrm{O}_{\mathrm{O}}^{\times}(\mathrm{YSZ})$ is a lattice oxygen and $\mathrm{V}_{\mathrm{O}}^{\prime \prime}$ (YSZ) is an oxygen vacancy. On the YSZ surface there can be three species, $\mathrm{O}^{2-}(\mathrm{YSZ}), \mathrm{OH}^{-}(\mathrm{YSZ})$, and $\mathrm{H}_{2} \mathrm{O}$ (YSZ), and empty sites (YSZ). Note that this nomenclature uses specific material names in place of generic names (i.e., "YSZ" is used instead of "el").

The hydrogen adsorption-desorption reaction (Eq. 32) also appears in the thermal heterogeneous chemistry (reactions 1 and 2 in Table I). Of the two charge-transfer reactions (reactions 34 and 33), we assume that reaction 34 is rate-limiting. Consequently, the other four reactions are assumed to be equilibrated. Further, we assume that the electrolyte surface is nearly fully covered by $\mathrm{O}^{2-}$ (YSZ). Using these assumptions, the current density can be written in a Butler-Volmer form as

$$
i=i_{0}\left[\exp \left(\frac{\left(\beta_{34, a}+1\right) F \eta_{a}}{R T}\right)-\exp \left(-\frac{\beta_{34, c} F \eta_{a}}{R T}\right)\right]
$$

where $\eta_{a}=E_{a}-E_{a}^{\mathrm{eq}}$ is the activation overpotential and the exchange current density is given as

$$
i_{0}=i_{\mathrm{H}_{2}}^{*} \frac{\left(p_{\mathrm{H}_{2}} / p_{\mathrm{H}_{2}}^{*}\right)^{1 / 4}\left(p_{\mathrm{H}_{2} \mathrm{O}}\right)^{3 / 4}}{1+\left(p_{\mathrm{H}_{2}} / p_{\mathrm{H}_{2}}^{*}\right)^{1 / 2}}
$$

The electric-potential difference between the anode and the electrolyte is $E_{a}$, and the equilibrium electric-potential difference $E_{a}^{\mathrm{eq}}$ is the electric-potential difference at which there is no net current flow. Note that the apparent symmetry factor in the anodic direction is now $\beta_{34, a}+1$, not $\beta_{34, a}$ (see the Appendix for more details). As has been discussed in prior literature, this shift in symmetry factor occurs where there are multiple charge-transfer steps, with one being rate-limiting. ${ }^{70}$ Note the relatively complex reaction orders in the exchange current density. They are quite different from those that might be anticipated from a single global charge-transfer reaction. The parameter $p_{\mathrm{H}_{2}}^{*}$ is determined from the balance between adsorption and desorption of hydrogen on the Ni.

The forward and reverse rates for hydrogen adsorption and desorption on $\mathrm{Ni}$ (Eq. 32) are still not definitively established, and they depend on such variables as the particular crystal face and surface defects. Here, we use the rates reported by Lapujoulade and Neil. ${ }^{53}$ The dissociative adsorption rate can be written simply in terms of a sticking probability $\gamma_{0}=0.01$. The desorption rate is written as

$$
q_{\text {des }}=k_{\text {des }}[\mathrm{H}]^{2}=A_{\text {des }} \exp \left(-\frac{E_{\mathrm{des}}}{R T}\right)[\mathrm{H}]^{2}=A_{\mathrm{des}} \exp \left(-\frac{E_{\mathrm{des}}}{R T}\right) \Gamma^{2} \theta_{\mathrm{H}}^{2}
$$

where the surface site density $\Gamma=2.6 \times 10^{-9} \mathrm{~mol} / \mathrm{cm}^{2}$, the preexponential factor $A_{\mathrm{des}}=5.59 \times 10^{19} \mathrm{~s} \mathrm{~cm}^{2} / \mathrm{mol}$, and the activation energy $E_{\text {des }}=88.12 \mathrm{~kJ} / \mathrm{mol}$.

The steady-state hydrogen surface coverage that results from the balance between adsorption and desorption may be expressed as

$$
\theta_{\mathrm{H}}=\frac{\left(p_{\mathrm{H}_{2}} / p_{\mathrm{H}_{2}}^{*}\right)^{1 / 2}}{1+\left(p_{\mathrm{H}_{2}} / p_{\mathrm{H}_{2}}^{*}\right)^{1 / 2}}
$$

where

$$
p_{\mathrm{H}_{2}}^{*}=\frac{A_{\mathrm{des}} \Gamma^{2} \sqrt{2 \pi R T W_{\mathrm{H}_{2}}}}{\gamma_{0}} \exp \left(-\frac{E_{\mathrm{des}}}{R T}\right)
$$

With $\gamma_{0}=0.01, p_{\mathrm{H}_{2}}^{*}$ varies from $0.7 \mathrm{~atm}$ at $700^{\circ} \mathrm{C}$ to $4.9 \mathrm{~atm}$ at $900^{\circ} \mathrm{C}$. The coverage varies from 0.54 at $700^{\circ} \mathrm{C}$ to 0.31 at $900^{\circ} \mathrm{C}$. The equilibrium constant $K_{32}$ can be written simply as $K_{32}=1 / p_{\mathrm{H}_{2}}^{*}$.
In principle, $i_{\mathrm{H}_{2}}^{*}$ can be derived from parameters associated with the charge-transfer reactions. However, parameters like specific three-phase boundary length and the elementary charge-transfer rates are not directly known. Thus, here we take $i_{\mathrm{H}_{2}}^{*}$ as an empirical constant. For the results shown in later sections, $i_{\mathrm{H}_{2}}=8.5 \mathrm{~A} / \mathrm{cm}^{2}$, which was adjusted to produce dilute-hydrogen button-cell performance consistent with measurements by Jiang and Virkar. ${ }^{71}$

Electrochemical reduction of oxygen.- The overall oxygen reduction and incorporation at the electrode-electrolyte interface can be written as

$$
\frac{1}{2} \mathrm{O}_{2}(\mathrm{~g})+\mathrm{V}_{\mathrm{O}}(\mathrm{el})+2 \mathrm{e}^{-}(\mathrm{c}) \rightleftharpoons \mathrm{O}_{\mathrm{O}}^{\times}(\mathrm{el})
$$

where $\mathrm{V}_{\mathrm{O}}(\mathrm{el})$ and $\mathrm{O}_{\mathrm{O}}^{\times}(\mathrm{el})$ denote the oxygen vacancies and lattice oxygen ions in the bulk of the electrolyte and $\mathrm{e}^{-}(\mathrm{c})$ are the electrons within the cathode. As with oxidation at the anode, the global reaction may be the result of elementary steps.

Here, we assume that oxygen reduction proceeds in two steps

1. Adsorption/desorption

$$
\mathrm{O}_{2}(\mathrm{~g})+2(\mathrm{c}) \rightleftharpoons 2 \mathrm{O}_{\mathrm{ad}}(\mathrm{c})
$$

2. Charge transfer and incorporation at the TPB

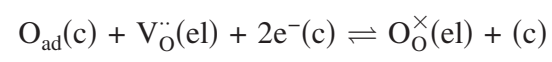

In these reactions $\mathrm{O}_{\mathrm{ad}}(\mathrm{c})$ is adsorbed atomic oxygen on the cathode surface and (c) is an unoccupied cathode surface site. The chargetransfer step is assumed to be rate-limiting.

A Butler-Volmer formulation can be derived and the details are provided in the Appendix. In short, the current density is expressed as

$$
i=i_{0}\left[\exp \left(\frac{\beta_{44, a} F \eta_{c}}{R T}\right)-\exp \left(-\frac{\beta_{44, c} F \eta_{c}}{R T}\right)\right]
$$

where the cathode activation overpotential is $\eta_{c}=E_{c}-E_{c}^{\mathrm{eq}}$.

Letting $p_{\mathrm{O}_{2}}^{*}=1 / K_{43}$, and $i_{\mathrm{O}_{2}}^{*}=2 \ell_{\mathrm{TPB}} F k_{44, a} K_{44}^{-\beta_{44, a}}$, and taking $\beta_{44, a}=1 / 2$, the exchange current density can be represented as

$$
i_{0}=i_{\mathrm{O}_{2}}^{*} \frac{\left(p_{\mathrm{O}_{2}} / p_{\mathrm{O}_{2}}^{*}\right)^{1 / 4}}{1+\left(p_{\mathrm{O}_{2}} / p_{\mathrm{O}_{2}}^{*}\right)^{1 / 2}} \text {. }
$$

For an LSM-YSZ interface, Matsuzaki and Yasuda ${ }^{72}$ presented an Arrhenius expression for $p_{\mathrm{O}_{2}}^{*}$ as

$$
p_{\mathrm{O}_{2}}^{*}=A_{\mathrm{O}_{2}} \exp \left(-E_{\mathrm{O}_{2}} / R T\right)
$$

where $A_{\mathrm{O}_{2}}=4.9 \times 10^{8} \mathrm{~atm}$, and $E_{\mathrm{O}_{2}}=200 \mathrm{~kJ} / \mathrm{mol}$. The parameter $i_{\mathrm{O}_{2}}^{*}$ is taken here as an empirical parameter that is adjusted to represent experimentally observed performance. ${ }^{71}$ For the results shown in subsequent sections, $i_{\mathrm{O}_{2}}^{*}=2.8 \mathrm{~A} / \mathrm{cm}^{2}$.

Challenges in elementary chemistry.- Within the three-phase regions, thermal heterogeneous reactions and electrochemical charge-transfer reactions proceed concurrently and competitively. For example, an adsorbed hydrogen $\mathrm{H}(\mathrm{Ni})$ may recombinatively desorb or it may participate in a charge-transfer reaction. There is current research devoted to developing fully coupled, elementary, thermal, and electrochemical reaction mechanisms. ${ }^{25-27}$ However, these studies are limited to idealized surfaces (e.g., patterned anodes) and hydrogen chemistry. Chan and Xia have developed models that incorporate the effects of distributed electronic and ionic potentials within porous cermet electrodes. ${ }^{10}$ Nevertheless, it remains a challenging long-term task to extend this research to hydrocarbon fuels and practical porous ceramic-metallic anode structures. In addition to purely chemical considerations, there is a mathemati- 


\begin{tabular}{lcr}
\hline \multicolumn{2}{l}{ Table II. Parameters for an SOFC MEA structure. } & \\
Parameters & Value & Units \\
\hline Anode & & \\
Thickness $\left(L_{a}\right)$ & 1220 & $\mu \mathrm{m}$ \\
Porosity $\left(\phi_{g}\right)$ & 0.35 & \\
Tortuosity $\left(\tau_{g}\right)$ & 3.50 & \\
Average pore radius $\left(r_{p}\right)$ & 0.50 & $\mu \mathrm{m}$ \\
Average particle diameter $\left(d_{p}\right)$ & 2.50 & $\mu \mathrm{m}$ \\
Specific catalyst area $\left(A_{s}\right)$ & 1080 & $\mathrm{~cm}^{-1}$ \\
Cathode & & \\
Thickness $\left(L_{c}\right)$ & 30 & $\mu \mathrm{m}$ \\
Porosity $\left(\phi_{g}\right)$ & 0.35 & \\
Tortuosity $\left(\tau_{g}\right)$ & 3.50 & \\
Average pore radius $\left(r_{p}\right)$ & 0.5 & $\mu \mathrm{m}$ \\
Average particle diameter $\left(d_{p}\right)$ & 2.5 & $\mu \mathrm{m}$ \\
Electrolyte: $\sigma_{\mathrm{el}}=\sigma_{0} T^{-1} \exp \left(-E_{\mathrm{el}} / R T\right)$ & & \\
Thickness $\left(L_{\mathrm{el}}\right)$ & 25 & $\mu \mathrm{m}$ \\
Activation energy of $\mathrm{O}^{2-}\left(E_{\mathrm{el}}\right)$ & $8.0 \times 10^{4}$ & $\mathrm{~J} / \mathrm{mol}$ \\
Pre-factor of $\mathrm{O}^{2-}\left(\sigma_{0}\right)$ & $3.6 \times 10^{5}$ & $\mathrm{~S} / \mathrm{cm}$ \\
Leakage overpotential $\left(\eta_{\max }\right)$ & 0.055 & $\mathrm{volts}$ \\
Leakage overpotential $\left(i_{\max }\right)$ & 8.0 & $\mathrm{~A} / \mathrm{cm}^{2}$
\end{tabular}

cal homogenization problem associated with modeling the distributed nanometer-scale three-phase-boundary interfaces within the first few micrometers of an anode structure.

The approach taken in this paper assumes a weak coupling between the thermal heterogeneous chemistry within bulk of the porous anode and the charge-transfer chemistry in the relatively thin three-phase region. The charge-transfer chemistry proceeds on the basis of the $\mathrm{H}_{2}$ concentration at the interface between the anode and the dense electrolyte. The hydrogen concentration depends on the heterogeneous reforming chemistry and transport within the porous anode. This approach neglects effects like any charge-transfer inhibition associated with other adsorbed species competing with adsorbed $\mathrm{H}(\mathrm{Ni})$. Nevertheless, the approach here represents a significant advance in the state-of-the-art of fuel cell modeling and provides practically useful results.

The analysis in this paper assumes that all charge-transfer chemistry proceeds through $\mathrm{H}_{2}$. Although this is a nearly universal assumption in SOFC modeling, it is also well known that cells can be run on even pure $\mathrm{CO} .{ }^{71}$ Thus, as the incorporation of elementary electrochemistry into SOFC modeling advances, it will be important to include multiple competing charge-transfer pathways in the electrochemical reaction mechanisms.

\section{Results and Discussion}

Two examples serve to demonstrate the model capabilities. The first uses button-cell information reported by Jiang and Virkar ${ }^{71}$ to help establish empirical parameters in the electrochemistry model by fitting MEA performance on mixtures of hydrogen and steam. The physical and electrochemical parameters of this MEA model are then used in an example that considers methane reforming in one channel of a planar SOFC.

The channel model assumes a $5 \mathrm{~cm}$ long fuel channel with a square cross section of $1 \mathrm{~mm}^{2}$. The electrochemically active perimeter is $P_{\mathrm{e}}=1.2 \mathrm{~mm}$, which is $0.2 \mathrm{~mm}$ wider than the channelelectrode interface. Oxygen depletion within the air channel is assumed to be negligible owing to the sufficient high air flow rate. We assume that $\mathrm{H}_{2}$ is the only electrochemically active fuel species and the charge-transfer chemistry is modeled in modified Butler-Volmer form as discussed in foregoing sections.

MEA performance with dilute hydrogen.- Jiang and Virkar reported cell-performance data measured in button cells using mixtures of $\mathrm{H}_{2}, \mathrm{CO}, \mathrm{H}_{2} \mathrm{O}$, and $\mathrm{CO}_{2}{ }^{71}$ These are especially valuable data because they quantify fuel-depletion effects on cell performance.
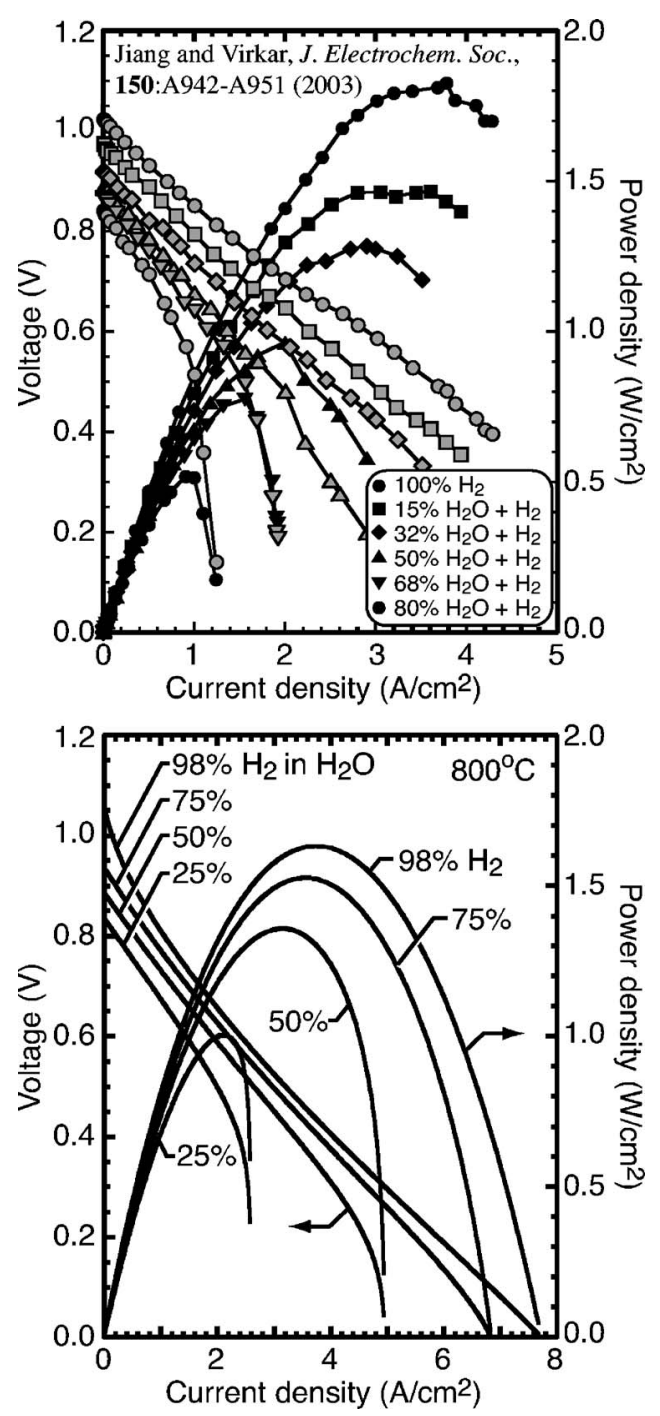

Figure 4. Computed MEA performance operating on different $\mathrm{H}_{2}-\mathrm{H}_{2} \mathrm{O}$ mixtures at $800^{\circ} \mathrm{C}$ and $1 \mathrm{~atm}$. The upper panel is a reproduction of experimental measurements by Jiang and Virkar (Ref. 71). The lower panel shows predictions from the MEA model.

The anode is a porous Ni-YSZ cermet that is $1.22 \mathrm{~cm}$ thick. The electrolyte is $25 \mu \mathrm{m}$ thick dense YSZ. The cathode is a $30 \mu \mathrm{m}$ thick porous LSM structure. Table II lists other physical parameters that we have used to describe the MEA structure.

Sometimes measured open-circuit potential is lower than the ideal reversible potential. One way to handle this behavior in the model is to assume some electronic current leakage through the electrolyte. In this case, Eq. 23 is modified by subtracting a leakage overpotential as

$$
E_{\text {cell }}=E_{\text {rev }}-\eta_{\text {act }, a}(i)-\eta_{\text {ohm }}(i)-\left|\eta_{\text {act }, c}(i)\right|-\eta_{\text {leak }}(i)
$$

In this somewhat ad hoc formulation, the leakage overpotential may be written as ${ }^{28}$

$$
\eta_{\text {leak }}=\eta_{\text {max }}\left(1-i / i_{\text {max }}\right)
$$

The parameters $\eta_{\max }$ and $i_{\max }$ (limiting current density) are determined empirically to represent measured MEA performance.

The approach described in this paper is used to model button-cell experiments. The channel is taken to be very short and the flow rates are sufficiently high so that there is essentially no depletion. Thus, the gas space in the anode and cathode compartments behaves as 


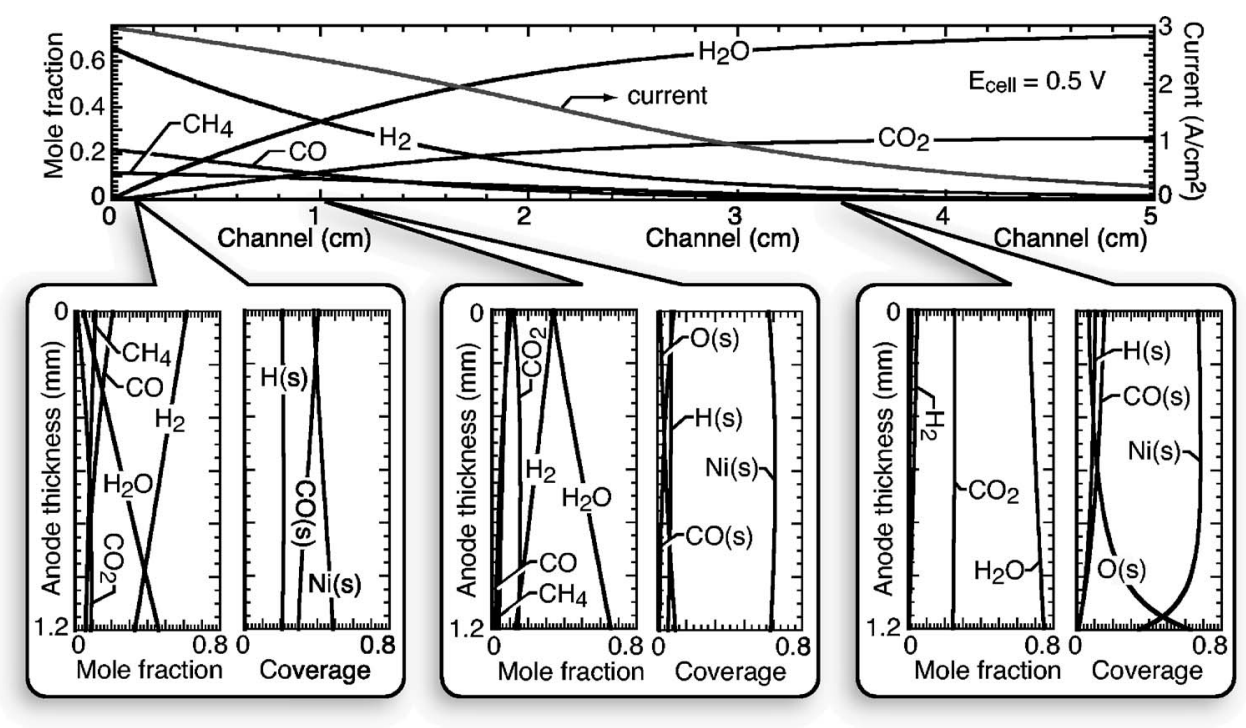

Figure 5. Solutions for a fuel-cell channel with a mixture of $66 \% \mathrm{H}_{2}$, $22 \% \mathrm{CO}$, and $12 \% \mathrm{CH}_{4}$ entering the anode channel at a mean velocity of $30 \mathrm{~cm} / \mathrm{s}$. Temperature is uniform at $800^{\circ} \mathrm{C}$ and the pressure is atmospheric. The upper panel shows gas-phase mole fractions as a function of distance along a $5 \mathrm{~cm}$ channel. The lower panels show gas-phase mole fractions and surface coverages through the thickness of the porous anode at three positions along the channel. The upper boundaries of the dropdown panels are at the anode-channel interface and the lower boundaries are at the anode-electrolyte interface.

stirred reactors adjacent to the porous electrodes. The parameters $i_{\mathrm{H}_{2}}^{*}$ and $i_{\mathrm{O}_{2}}^{*}$ (Eq. 38 and 46) are adjusted to achieve measured limiting current densities and maximum power densities.

Figure 4 illustrates voltage-current performance of the MEA operating on $\mathrm{H}_{2}-\mathrm{H}_{2} \mathrm{O}$ mixtures at $800^{\circ} \mathrm{C}$ and $1 \mathrm{~atm}$. The upper panel reproduces Fig. 5 of Jiang and Virkar, ${ }^{71}$ showing measured performance with various levels of steam dilution. The lower panel shows results computed from the MEA model. Although the fit is not perfect, the MEA model is in very reasonable agreement with the experimental observations. The open-circuit voltage is reduced with increasing dilution, as is the limiting current density. Especially at the higher dilution levels, the limiting current is influenced strongly by transport limitations through the porous anode.

Heterogeneous reforming in the anode. - In this example the anode fuel stream is a mixture of $66 \% \mathrm{H}_{2}, 22 \% \mathrm{CO}$, and $12 \% \mathrm{CH}_{4}$. This mixture is essentially the gas-phase chemical equilibrium composition that results from an initial mixture of $60 \% \mathrm{CH}_{4}$ and $40 \%$ $\mathrm{H}_{2} \mathrm{O}$ at $800^{\circ} \mathrm{C}$, which might be the result of some upstream reforming process. The inlet velocity is $30 \mathrm{~cm} / \mathrm{s}$ and the cell is maintained at a uniform temperature of $800^{\circ} \mathrm{C}$ and $1 \mathrm{~atm}$. The cell potential is held uniform at $E_{\text {cell }}=0.5 \mathrm{~V}$. Figure 5 illustrates the predicted species distributions in the channel and within the anode structure.

Flowing along the length of the channel, the gas-phase mole fractions of fuel species $\mathrm{CH}_{4}, \mathrm{CO}$, and $\mathrm{H}_{2}$ decrease while the fractions of the products $\mathrm{H}_{2} \mathrm{O}$ and $\mathrm{CO}_{2}$ increase. The current density decreases along the channel length. This is the result of the lower electrochemical potential of an increasingly depleted fuel stream. At the channel exit the current density is reduced to $i \approx 0.2 \mathrm{~A} / \mathrm{cm}^{2}$, because the fuel has been mostly consumed.

The gas-phase composition profiles within the anode pores (left panels of the drop-down panels in Fig. 5) assist interpretation of the chemistry and transport processes within the anode. As inferred by their concentration gradients, $\mathrm{CH}_{4}, \mathrm{CO}$, and $\mathrm{H}_{2}$ are transported from the channel into the anode. Electrochemical charge-transfer reaction produces steam at the interface with the dense electrolyte (i.e., at the bottom of the drop-down panels). As the steam is transported back toward the channel it encounters $\mathrm{CH}_{4}$ and $\mathrm{CO}$. The thermal heterogeneous chemistry (Table I) on the Ni surfaces leads to reforming of the $\mathrm{CH}_{4}$, producing $\mathrm{CO}$ and $\mathrm{H}_{2}$. The $\mathrm{CO}$ also reacts with steam, shifting toward more $\mathrm{H}_{2}$ and $\mathrm{CO}_{2}$. The reforming and shifting behavior persists within the anode until the $\mathrm{CH}_{4}$ and $\mathrm{CO}$ are largely consumed by about $3 \mathrm{~cm}$ along the channel.

The graphs on the right in the drop-down panels of Fig. 5 show predicted surfaces coverages through the anode thickness. Early in the channel, there is considerable coverage of the Ni surfaces by
$\mathrm{H}(\mathrm{s})$ and $\mathrm{CO}(\mathrm{s})$. However, as the fuel is depleted in the downstream sections the open $\mathrm{Ni}(s)$ site fraction increases. In the far downstream sections after even the $\mathrm{H}_{2}$ is depleted, the large $\mathrm{H}_{2} \mathrm{O}$ concentrations lead to relatively high surface coverage by $\mathrm{O}(\mathrm{s})$. This behavior is seen in the right-most drop-down panel near the dense-electrolyte interface.

Figure 6 illustrates several interesting effects of the transport and chemistry across the anode thickness. Two reversible electricpotential differences (Nernst potentials) are shown as a function of position along the channel. They are evaluated between the channel gases and the air channel. They are also evaluated between the gases at the dense electrolyte interface and the air channel. In both cases only $\mathrm{H}_{2}$ is considered as the fuel that participates in charge transfer. The difference between the reversible potentials in the channel and at the electrolyte interface $\Delta E$ is the concentration overpotential. For the circumstances in this simulation, the anode concentration overpotential is seen to range between 0.1 and $0.2 \mathrm{~V}$. In this model, which solves the detailed reactive porous-media problem within the anode, there is no need to specifically involve the concentration overpotential. Nevertheless, it is interesting to evaluate the loss in potential associated with species transport and chemistry in the anode. In principle, these losses could be reduced using alternative designs. For example, opening the pore structure could reduce transport losses. In the engineering of functionally graded electrode structures, models such as these provide quantitative insight in evaluating alternative designs.

As illustrated in Fig. 6, there is a net pressure gradient through the anode thickness, with a higher pressure at the electrolyte interface. The pressure increase is primarily due to the net mass addition by virtue of oxygen-ion flux through the electrolyte and the flow

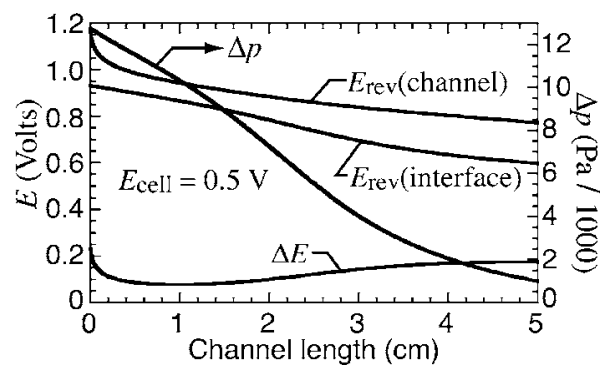

Figure 6. Electric potentials and pressure difference across the anode as a function position in the channel for the solution shown in Fig. 5. 


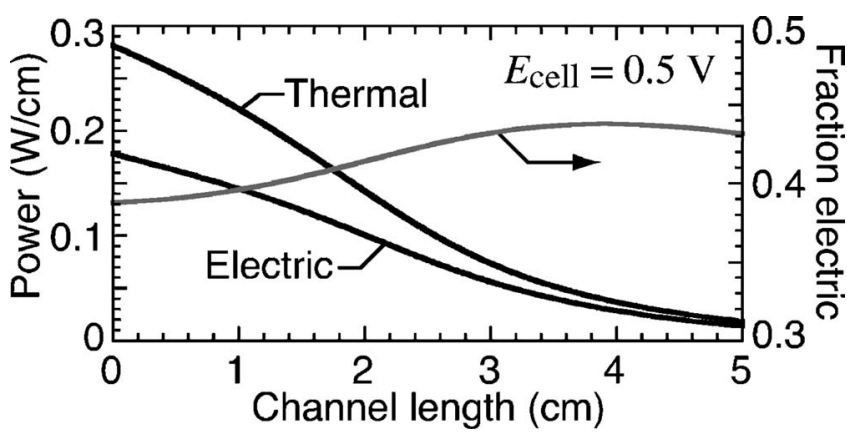

Figure 7. Local thermal and electrical power levels as a function position in the channel for the solution shown in Fig. 5. Also shown is the fraction of the net power that is electrical.

resistance caused by the electrode pore structure. For the circumstances here, the net pressure difference across the anode varies from around 12,000 Pa near the channel entrance where the current density is high to around $1000 \mathrm{~Pa}$ near the channel exit. These pressure differences affect the species transport via the dusty-gas model (Eq. 11). Changes in the local gas-phase mole number, which can result from the reforming chemistry, also affect the local pressure variations. Potentially there are structural-design issues associated with relatively large pressure gradients across the anode.

Although a uniform temperature is imposed, it is important to understand the thermal consequences of the chemistry and transport. Specifically, the heat release due to thermal chemistry and various overpotential losses can be determined. This local heat release is the basis of the source term that would appear in a thermal energy equation. At steady state the local heat release (per unit length along the channel) can be determined as

$$
q^{\prime}(x)=\frac{d}{d x}\left(\dot{m}_{a} h_{a}+\dot{m}_{c} h_{c}\right)-P_{e} i E_{\text {cell }}
$$

where $\dot{m}=\rho u A_{c}$ and $h=\Sigma Y_{k} h_{k}$ are the mass flow rates and the specific enthalpies within the anode (subscript "a") and cathode (subscript "c") flow channels, respectively, and $E_{\text {cell }}$ is the cell voltage. Both $\dot{m}$ and $h$ vary along the channel as a result of oxygen-ion transport through the electrolyte as well as the thermal and electrochemical reactions in the electrodes. The last term in Eq. 50 represents the electrical power (per unit length) produced by the cell. The net heat release is the difference between the change in chemical availability (i.e., $\dot{m} h$ ) and the power delivered in the form of electricity. Note that the net heat release is the result of several competing factors. The reforming chemistry is endothermic, but the ohmic resistance associated with ion transport through the electrolyte and inefficiencies associated with charge-transfer chemistry are exothermic. Self-sustained SOFC operation depends on the net heat release to maintain the high operating temperatures.

Figure 7 illustrates some of the thermal consequences associated with the heterogeneous chemistry and the electrochemical losses. Near the channel entrance where the current density is high, both the thermal losses and the electric power are relatively high. As the fuel is depleted and the current density decreases, both the thermal heat release and the electric power decrease along the length of the channel. Throughout the channel, the electrical-to-thermal ratio remains roughly in the range of 40 to $45 \%$. This relatively low efficiency is a result of the low operating voltage $\left(E_{\text {cell }}=0.5 \mathrm{~V}\right)$. Near the channel entrance the higher current density contributes to relatively higher overpotential losses. Later in the channel the electrical fraction increases owing to reduced losses at lower current density.

The cell efficiency may be evaluated from the solution as

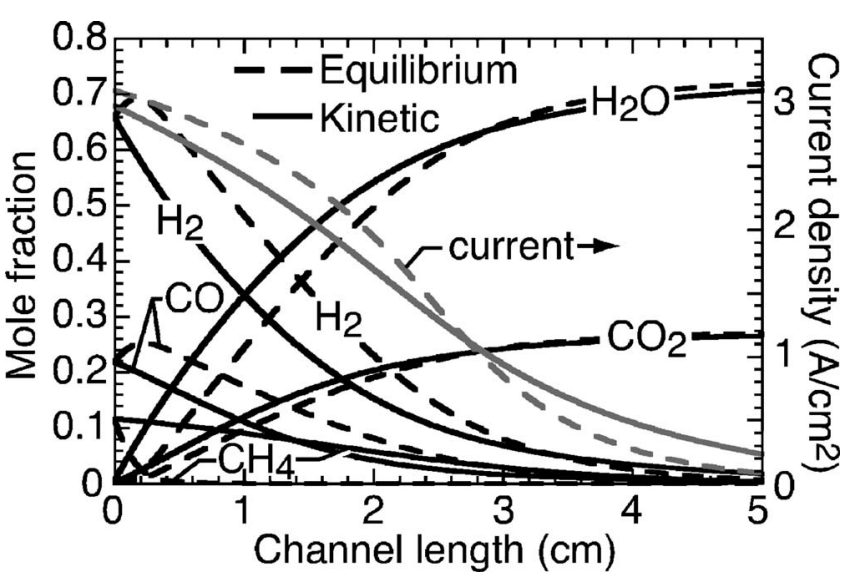

Figure 8. Predicted gas-phase channel mole fractions and current-density profiles assuming either heterogeneous kinetics (Table I) or chemical equilibrium with the porous anode structure. The operating conditions are the same as those in Fig. 5 and the kinetic solution is simply replotted here to show the comparison.

$$
\varepsilon=\frac{W_{e}}{Q_{\text {in }}}=\frac{\int i E_{\text {cell }} d A}{\dot{m}_{f, \text { in }} \Delta h_{f, \text { in }}}
$$

where $W_{e}$ is the electrical work output and $Q_{\text {in }}$ is the heat that would be released upon full oxidation of the inlet fuel stream. The inlet fuel mass flow rate is $\dot{m}_{f, \text { in }}$ and $\Delta h_{f, \text { in }}$ is the specific enthalpy associated with completely oxidizing the fuel stream. The electrical work is the product of the current density $i$ and operating voltage $E_{\text {cell }}$, integrated over the active membrane-electrode assembly (MEA) area. In this case the efficiency is found to be $\varepsilon=39.2 \%$. Noting from Fig. 5 that some $\mathrm{H}_{2}$ remains in the exhaust stream, it is reasonable that the actual efficiency is a bit lower than the roughly $40 \%$ efficiency indicated by Fig. 7, which does not consider fuel utilization. By increasing the operating voltage to $E_{\text {cell }}=0.8 \mathrm{~V}$, the efficiency can be increased to nearly $60 \%$. In this case the current density is considerably lower throughout the cell. However, achieving the high efficiency requires that the cell be extended to nearly $25 \mathrm{~cm}$ long.

It is interesting to evaluate the importance of heterogeneous kinetics within the electrode. One approach is to consider the cell behavior for the limiting case that fuel-reforming and water-gasshift processes are equilibrated within the anode. A de facto equilibrium can be established by imposing very high rates for the following two global reversible reactions

$$
\begin{gathered}
\mathrm{CH}_{4}+\mathrm{H}_{2} \mathrm{O} \rightleftharpoons 3 \mathrm{H}_{2}+\mathrm{CO} \\
\mathrm{CO}+\mathrm{H}_{2} \mathrm{O} \rightleftharpoons \mathrm{H}_{2}+\mathrm{CO}_{2}
\end{gathered}
$$

Because these global reactions involve only gas-phase species, the equilibrium constants are easily evaluated.

Figure 8 compares gas-phase species and current-density profiles along channel length. The kinetics and equilibrium models show qualitatively similar behavior. However, there are some notable differences. The equilibrium case indicates significantly more rapid reforming and depletion of the initial $\mathrm{CH}_{4}$, leading to initially higher levels of $\mathrm{H}_{2}$ and $\mathrm{CO}$. The equilibrium solution tends to "trap" more of the carbon as $\mathrm{CO}$, somewhat impeding the ultimate conversion to $\mathrm{CO}_{2}$. The current-density profiles for the equilibrium situation are higher in the upstream sections and lower downstream. This is due to the higher $\mathrm{H}_{2}$ and $\mathrm{CO}$ concentrations predicted by the equilibrium in the channel-entrance regions. In spite of the local differences, the cell performance integrated over the entire channel is quite similar for the two cases. 


\section{Conclusions}

We have developed a model that considers the coupled effects of channel flow, porous-media electrode transport, heterogeneousreforming and partial-oxidation chemistry, and electrochemistry in solid-oxide fuel cells operating $\mathrm{CH}_{4}, \mathrm{H}_{2}$, and $\mathrm{CO}$. The electrochemical parameters of the model are in concert with experimentally measured button-cell performance operating on dilute hydrogen. The heterogeneous chemical reaction mechanism is validated through analysis of oxidative steam reforming of methane on Ni catalysts. The model can be applied to investigate alternative design and operating conditions, seeking to enhance understanding and interpretation of the underlying physical and chemical processes. The underlying approaches for representing chemistry and transport are well suijlted for incorporation into larger systems-level software that also include three-dimensional heat transfer and fluid flow.

\section{Acknowledgments}

This work was supported by the DoD Multidisciplinary University Research Initiative (MURI) program administered by the Office of Naval Research under grant N00014-02-1-0665. We gratefully acknowledge many insightful discussions with Professor Greg Jackson (University of Maryland) and Professor Tony Dean (Colorado School of Mines). We are especially grateful to Renate Schwiedernoch, Benjamin Schädel, and Luba Maier (all of University of Karlsruhe) for sharing their work on the Ni reaction mechanism prior to its publication.

\section{Appendix \\ Derivation of Modified Butler-Volmer Equations}

The intent of this appendix is to fill in some of the details in the analysis between elementary charge-transfer reaction steps and a Butler-Volmer formulation.

Hydrogen oxidation.- For the hydrogen oxidation, as summarized in the Electrochemistry section, five reaction steps are considered in the anode three-phase region. These reactions involve six surface species and two gas-phase species. There are a number of constraints that must be satisfied among the coverages of the surface species. By definition the site fractions on the metal and on the electrolyte must sum to unity; that is

$$
\begin{gathered}
\theta_{\mathrm{H}}+\theta_{\mathrm{Ni}}=1 \\
\theta_{\mathrm{O}}+\theta_{\mathrm{OH}}+\theta_{\mathrm{H}_{2} \mathrm{O}}+\theta_{\mathrm{YSZ}}=1
\end{gathered}
$$

The site fractions are defined as follows: $\theta_{\mathrm{H}}$ is adsorbed atomic hydrogen on the anode $\mathrm{H}(\mathrm{Hi}) ; \theta_{\mathrm{Ni}}$ is an empty site on the anode $(\mathrm{Ni}) ; \theta_{\mathrm{O}}$ represents $\mathrm{O}_{\mathrm{ad}}^{2-}(\mathrm{YSZ}) ; \theta_{\mathrm{OH}}$ represents $\mathrm{OH}_{\mathrm{ad}}^{-}(\mathrm{YSZ}) ; \theta_{\mathrm{H}_{2} \mathrm{O}}$ represents $\mathrm{H}_{2} \mathrm{O}_{\mathrm{ad}}(\mathrm{YSZ})$; and $\theta_{\mathrm{YSZ}}$ represents an empty site on the electrolyte surface (YSZ).

Assuming that only reaction 34 is rate-limiting, the species activities (i.e., partial pressures $p_{k}$ and surface coverages $\theta_{k}$ ) can be related through equilibrium constants $K_{i}$ of the fast reactions as

$$
\begin{gathered}
\frac{\theta_{\mathrm{H}}^{2}}{\theta_{\mathrm{Ni}}^{2} p_{\mathrm{H}_{2}}}=K_{32} \\
\frac{\theta_{\mathrm{Ni}} \theta_{\mathrm{OH}}}{\theta_{\mathrm{H}} \theta_{\mathrm{O}}}=K_{33} \exp \left(\frac{F E_{a}}{R T}\right) \\
\frac{\theta_{\mathrm{YSZ}} p_{\mathrm{H}_{2} \mathrm{O}}}{\theta_{\mathrm{H}_{2} \mathrm{O}}}=K_{35} \\
\frac{\theta_{\mathrm{YSZ}}}{\theta_{\mathrm{O}}}=K_{36}
\end{gathered}
$$

Because it is a charge-transfer reaction, the equilibrium for reaction 33 involves the electric-potential difference between the electrode and electrolyte $E_{a}$. Assume that the rate of reaction 33 can be written in elementary form as

$$
i=\ell_{\mathrm{TPB}} F\left[k_{33, a} \theta_{\mathrm{H}} \theta_{\mathrm{O}} \exp \left(\frac{\beta_{33, a} F E_{a}}{R T}\right)-k_{33, c} \theta_{\mathrm{OH}} \theta_{\mathrm{Ni}} \exp \left(-\frac{\beta_{33, c} F E_{a}}{R T}\right)\right]
$$

where $k_{33, a}$ and $k_{33, c}$ are the anodic and cathodic thermal rate constants (which are functions of temperature), $\beta_{33, a}$ and $\beta_{33, c}$ are the anodic and cathodic symmetric factors with $\beta_{33, a}+\beta_{33, c}=1$, and $\ell_{\mathrm{TPB}}$ is the TPB length. When in equilibrium, the net current density vanishes $(i=0)$ and Eq. A-4 follows, with $K_{33}=k_{33, a} / k_{33, c}$. As discussed below, reasonable estimates of the hydrogen adsorption-desorption rates are available.

Assuming it is an elementary reaction, the current density $i$ of the rate-limiting reaction 34 is written as

$$
i=\ell_{\mathrm{TPB}} F\left[k_{34, a} \theta_{\mathrm{H}} \theta_{\mathrm{OH}} \exp \left(\frac{\beta_{34, a} F E_{a}}{R T}\right)-k_{34, c} \theta_{\mathrm{H}_{2} \mathrm{O}} \theta_{\mathrm{Ni}} \exp \left(-\frac{\beta_{34, c} F E_{a}}{R T}\right)\right]
$$

Recognizing that $\theta_{\mathrm{H}}+\theta_{\mathrm{Ni}}=1$ and $\theta_{\mathrm{O}}+\theta_{\mathrm{OH}}+\theta_{\mathrm{H}_{2} \mathrm{O}}+\theta_{\mathrm{el}}=1$, and with considerable algebraic manipulation, each of the site fractions on the YSZ surface can be written explicitly in terms of gaseous partial pressures and the surface coverages on the anode $\left(\theta_{\mathrm{H}}\right.$ and $\left.\theta_{\mathrm{Ni}}\right)$

$$
\begin{gathered}
\theta_{\mathrm{H}_{2} \mathrm{O}}=\frac{p_{\mathrm{H}_{2} \mathrm{O}}}{p_{\mathrm{H}_{2} \mathrm{O}}+K_{35}+K_{35} / K_{36}+\left(\theta_{\mathrm{H}} / \theta_{\mathrm{Ni}}\right) K_{33} \exp \left(F E_{a} / R T\right) K_{35} / K_{36}} \\
\theta_{\mathrm{YSZ}}=\frac{K_{35}}{p_{\mathrm{H}_{2} \mathrm{O}}+K_{35}+K_{35} / K_{36}+\left(\theta_{\mathrm{H}} / \theta_{\mathrm{Ni}}\right) K_{33} \exp \left(F E_{a} / R T\right) K_{35} / K_{36}} \\
\theta_{\mathrm{O}}=\frac{K_{35} / K_{36}}{p_{\mathrm{H}_{2} \mathrm{O}}+K_{35}+K_{35} / K_{36}+\left(\theta_{\mathrm{H}} / \theta_{\mathrm{Ni}}\right) K_{33} \exp \left(F E_{a} / R T\right) K_{35} / K_{36}} \\
\theta_{\mathrm{OH}}=\frac{\left(\theta_{\mathrm{H}} / \theta_{\mathrm{Ni}}\right) K_{33} \exp \left(F E_{a} / R T\right) K_{35} / K_{36}}{p_{\mathrm{H}_{2} \mathrm{O}}+K_{35}+K_{35} / K_{36}+\left(\theta_{\mathrm{H}} / \theta_{\mathrm{Ni}}\right) K_{33} \exp \left(F E_{a} / R T\right) K_{35} / K_{36}}
\end{gathered}
$$

Substituting the surface coverages from the equilibrium constraints and doing considerably more algebraic manipulation yields

$$
\begin{aligned}
i= & \ell_{\mathrm{TPB}} F k_{34, a} \frac{K_{32} K_{33} K_{35}}{K_{36}} \times\left\{( 1 + K _ { 3 2 } ^ { 1 / 2 } p _ { \mathrm { H } _ { 2 } } ^ { 1 / 2 } ) \left[p_{\mathrm{H}_{2} \mathrm{O}}+K_{35}+\frac{K_{35}}{K_{36}}\right.\right. \\
& \left.\left.+K_{33} \frac{K_{35}}{K_{36}} K_{32}^{1 / 2} p_{\mathrm{H}_{2}}^{1 / 2} \exp \left(\frac{F E_{a}}{R T}\right)\right]\right\}^{-1}\left\{p_{\mathrm{H}_{2}} \exp \left(\frac{\left(\beta_{34, a}+1\right) F E_{a}}{R T}\right)\right. \\
& \left.-\left(\frac{K_{34} K_{32} K_{33} K_{35}}{K_{36}}\right)^{-1} p_{\mathrm{H}_{2} \mathrm{O}} \exp \left(-\frac{\beta_{34, c} F E_{a}}{R T}\right)\right\}
\end{aligned}
$$

Seeking to put the current-density equation into Butler-Volmer form, the equilibrium electric potential is needed. Assuming that $\beta_{34, a}+\beta_{34, c}=1$, the equilibrium electric potential at $i=0$ is found as

$$
-\frac{2 F E_{a}^{\mathrm{eq}}}{R T}=\ln \left(\frac{K_{34} K_{32} K_{33} K_{35}}{K_{36}} \frac{p_{\mathrm{H}_{2}}}{p_{\mathrm{H}_{2} \mathrm{O}}}\right)
$$

In Butler-Volmer form, the current density is written compactly as

$$
i=i_{0}\left[\exp \left(\frac{\left(\beta_{34, a}+1\right) F \eta_{a}}{R T}\right)-\exp \left(-\frac{\beta_{34, c} F \eta_{a}}{R T}\right)\right]
$$

where $\eta_{a}=E_{a}-E_{a}^{\mathrm{eq}}$ is the activation overpotential. Note that the apparent symmetry factor in the anodic direction has become $\beta_{34, a}+1$, not $\beta_{34, a}$. This is the result of substituting the expression for $\theta_{\mathrm{OH}}$ (Eq. A-12), which contains the electric-potential difference, into the mass-action kinetics expression (Eq. A-8). Following further algebraic manipulation, the exchange current density $i_{0}$ is found to be

$$
\begin{aligned}
i_{0}= & \ell_{\mathrm{TPB}} F k_{34, c}\left(K_{34} \frac{K_{32} K_{33} K_{35}}{K_{36}}\right)^{\left(\beta_{34, c} / 2\right)} p_{\mathrm{H}_{2}}^{\left(\beta_{34,} / 2\right)} p_{\mathrm{H}_{2} \mathrm{O}}^{\left(1-\beta_{34,} / 2\right)}\left\{( 1 + K _ { 3 2 } ^ { 1 / 2 } p _ { \mathrm { H } _ { 2 } } ^ { 1 / 2 } ) \left[p_{\mathrm{H}_{2} \mathrm{O}}+K_{35}\right.\right. \\
& \left.\left.+\frac{K_{35}}{K_{36}}+\frac{K_{33} K_{35}}{K_{36}} K_{32}^{1 / 2} p_{\mathrm{H}_{2}}^{1 / 2} \exp \left(\frac{F E_{a}^{\mathrm{eq}}}{R T}\right)\right]\right\}^{-1}
\end{aligned}
$$

The Butler-Volmer expression can be simplified further by assuming that the YSZ surface is nearly fully covered with $\mathrm{O}_{\mathrm{ad}}^{2-}(\mathrm{el})$ (i.e., $\left.\theta_{\mathrm{O}} \approx 1\right)$. In this case

$$
i_{0}=\ell_{\mathrm{TPB}} F k_{34, c}\left(K_{34}, K_{32} K_{33}\right)^{\left(\beta_{34, c^{\prime}}\right)}\left(\frac{K_{36}}{K_{35}}\right)^{\left(1-\beta_{34, c} / 2\right)} \frac{p_{\mathrm{H}_{2}}^{\left(\beta_{34, c} / 2\right)} p_{\mathrm{H}_{2} \mathrm{O}}^{\left(1-\beta_{34, c} / 2\right)}}{1+K_{32}^{1 / 2} p_{\mathrm{H}_{2}}^{1 / 2}}
$$

This path to this simplification can be seen by substituting Eq. A-3 into Eq. A-16 to replace $\theta_{\mathrm{H}} / \theta_{\mathrm{Ni}}$ and recognizing that the denominator of Eq. A-11 is the same as a group of terms in Eq. A-16. Further restricting attention to the case that $\beta_{34, c}=1 / 2$, the exchange current density simplifies to

$$
i_{0}=\ell_{\mathrm{TPB}} F k_{34, c}\left(K_{34} K_{32} K_{33}\right)^{1 / 4}\left(\frac{K_{36}}{K_{35}}\right)^{3 / 4} \frac{p_{\mathrm{H}_{2}}^{1 / 4} p_{\mathrm{H}_{2} \mathrm{O}}^{3 / 4}}{1+K_{32}^{1 / 2} p_{\mathrm{H}_{2}}^{1 / 2}}
$$

The leading group of factors that involves a rate constant and several equilibrium constants is a function of temperature alone. For the purposes here, that group of terms is simply aggregated into a single empirically determined variable. The last factor, which represents how the current density depends on gas-phase partial pressures, reveals the apparent reaction order of the charge transfer.

There are two charge-transfer reactions, with reaction 34 assumed to be ratelimiting and reaction 33 assumed to be in equilibrium. Thus, the overall current density is twice the current density resulting from reaction 34 . The notation is simplified by collecting terms in the lead coefficient of Eq. A-18 and defining

$$
i_{\mathrm{H}_{2}}^{*}=2 \ell_{\mathrm{TPB}} F k_{34, c}\left(K_{34} K_{33}\right)^{1 / 4}\left(K_{36} / K_{35}\right)^{3 / 4}
$$

The exchange current density can be rewritten as 


$$
i_{0}=i_{\mathrm{H}_{2}}^{*} \frac{\left(p_{\mathrm{H}_{2}} / p_{\mathrm{H}_{2}}^{*}\right)^{1 / 4}\left(p_{\mathrm{H}_{2} \mathrm{O}}\right)^{3 / 4}}{1+\left(p_{\mathrm{H}_{2}} / p_{\mathrm{H}_{2}}^{*}\right)^{1 / 2}}
$$

In this way, the modified Butler-Volmer equation (Eq. A-15) represents the net current density in the anode-electrolyte triple-phase region. Because in practice the constants that comprise $i_{\mathrm{H}_{2}}^{*}$ are not known, $i_{\mathrm{H}_{2}}^{*}$ is used as an empirical parameter that can be adjusted to fit measured fuel-cell performance. The parameter $p_{\mathrm{H}_{2}}^{*}$ is defined in the text.

The important part of this analysis is to help understand the apparent reaction orders of the charge-transfer process. As seen from Eq. A-20, the reactions orders can be very different from those that might be anticipated from a single global charge-transfer reaction. In particular, note that the exchange current density has a positive order with respect to $\mathrm{H}_{2} \mathrm{O}$. This is in agreement with experimental observations, even though water does not play a catalytic role in this reaction mechanism. The reason for the $\mathrm{H}_{2} \mathrm{O}$ order dependence comes results from introducing $E_{a}^{\text {eq }}$ (Eq. A-14) to express the current density in terms of the overpotential $\eta_{a}$ instead of the electric-potential difference $E_{\mathrm{a}}$.

Oxygen reduction.- As discussed in the body of this paper, we assume two reaction steps for the electrochemical reduction of oxygen: an adsorption-desorption step and a charge-transfer step. The charge-transfer step is assumed to be rate-limiting. It is usually reasonable to assume that the surface site density of the cathode and the concentrations of $\mathrm{V}_{\mathrm{O}}^{*}$ and $\mathrm{O}_{\mathrm{O}}^{\times}$in the bulk of the electrolyte are constant.

Assuming the $\mathrm{O}_{2}$ adsorption-desorption is equilibrated, the equilibrium relationship provides that

$$
\frac{p_{\mathrm{O}_{2}} \theta_{c}^{2}}{\theta_{\mathrm{O}}^{2}}=K_{43}
$$

where $\theta_{\mathrm{O}}$ and $\theta_{c}$ are the site fractions of $\mathrm{O}_{\mathrm{ad}}(c)$ and $\mathrm{S}(c)$ on the cathode surface and $p_{\mathrm{O}_{2}}$ is the gas-phase partial pressure. With the constraint that $\theta_{\mathrm{O}}+\theta_{c}=1$, the site fractions can be written explicitly as

$$
\begin{aligned}
& \theta_{\mathrm{O}}=\frac{K_{43}^{1 / 2} p_{\mathrm{O}_{2}}^{1 / 2}}{1+K_{43}^{1 / 2} p_{\mathrm{O}_{2}}^{1 / 2}} \\
& \theta_{c}=\frac{1}{1+K_{43}^{1 / 2} p_{\mathrm{O}_{2}}^{1 / 2}}
\end{aligned}
$$

The current density through Reaction 44 can be written in elementary form as

$$
i=2 \ell_{\mathrm{TPB}} F\left[k_{44, a} \theta_{c} \exp \left(\frac{\beta_{44, a} F E_{c}}{R T}\right)-k_{44, c} \theta_{\mathrm{O}} \exp \left(-\frac{\beta_{44, c} F E_{c}}{R T}\right)\right]
$$

where $E_{c}$ is the electric-potential difference between the cathode and the electrolyte. Substituting expressions for the surface site fractions, the current density can be rewritten as

$$
i=\frac{2 \ell_{\mathrm{TPB}} F k_{44, a}}{1+K_{43}^{1 / 2} p_{\mathrm{O}_{2}}^{1 / 2}}\left[\exp \left(\frac{\beta_{44, a} F E_{c}}{R T}\right)-K_{44}^{-1} K_{43}^{1 / 2} p_{\mathrm{O}_{2}}^{1 / 2} \exp \left(-\frac{\beta_{44, c} F E_{c}}{R T}\right)\right]
$$

where $K_{44}=k_{44, a} / k_{44, c}$

At zero current density, the equilibrium electrical potential $E_{c}^{\mathrm{eq}}$ is found as

$$
\frac{F E_{c}^{\mathrm{eq}}}{R T}=\ln \left[K_{44}^{-1} K_{43}^{1 / 2} p_{\mathrm{O}_{2}}^{1 / 2}\right]
$$

The exchange current density follows as

$$
i_{0}=2 \ell_{\mathrm{TPB}} F k_{44, a} K_{44}^{-\beta_{44, a}} \frac{K_{43}^{\left(\beta_{44, a} / 2\right)} p_{\mathrm{O}_{2}}^{\left(\beta_{44, a} / 2\right)}}{1+K_{43}^{1 / 2} p_{\mathrm{O}_{2}}^{1 / 2}}
$$

In Butler-Volmer form, the current density is expressed as

$$
i=i_{0}\left[\exp \left(\frac{\beta_{44, a} F \eta_{c}}{R T}\right)-\exp \left(-\frac{\beta_{44, c} F \eta_{c}}{R T}\right)\right]
$$

where the cathode activation overpotential is $\eta_{c}=E_{c}-E_{c}^{\mathrm{eq}}$

To simplify the notation somewhat, define $p_{\mathrm{O}_{2}}^{*} \equiv 1 / K_{43}$, and $i_{\mathrm{O}_{2}}^{*}$ $\equiv 2 \ell_{\mathrm{TPB}} F k_{44, a} K_{44}^{-\beta_{44, a}}$. Assuming that $\beta_{44, a}=1 / 2$, the exchange current density is rewritten compactly as

$$
i_{0}=i_{\mathrm{O}_{2}}^{*} \frac{\left(p_{\mathrm{O}_{2}} / p_{\mathrm{O}_{2}}^{*}\right)^{1 / 4}}{1+\left(p_{\mathrm{O}_{2}} / p_{\mathrm{O}_{2}}^{*}\right)^{1 / 2}}
$$

As is the situation at the anode, the constants that comprise $i_{\mathrm{O}_{2}}^{*}$ are generally not known. Thus, $i_{\mathrm{O}_{2}}^{*}$ is used as a parameter to fit experimental observation. The important outcome of the analysis insight concerns the reaction order for the gas-phase oxygen.

For the LSM/YSZ interface, Matsuzaki and Yasuda ${ }^{72}$ represented $p_{\mathrm{O}_{2}}^{*}$ in Arrhenius form as

$$
p_{\mathrm{O}_{2}}^{*}=A_{\mathrm{O}_{2}} \exp \left(-E_{\mathrm{O}_{2}} / R T\right)
$$

where $A_{\mathrm{O}_{2}}=4.9 \times 10^{8}$ atm, and $E_{\mathrm{O}_{2}}=200 \mathrm{~kJ} / \mathrm{mol}$.

\section{References}

1. Z. Zhan, J. Liu, and S. A. Barnett, Appl. Catal., A, 262, 255 (2004).

2. C. Lu, W. L. Worrell, R. J. Gorte, and J. M. Vohs, J. Electrochem. Soc., 150, A354 (2003)

3. S. Campanari and P. Iora, J. Power Sources, 132, 113 (2004)

4. S. Campanari and P. Iora, Fuel Cells, 5, 34 (2005).

5. N. Autissier, D. Larrain, J. Van herle, and D. Favrat, J. Power Sources, 131, 313 (2004).

6. K. P. Pecknagle, R. E. Williford, L. A. Chick, D. R. Rector, and M. A. Khaleel, $J$. Power Sources, 113, 109 (2003).

7. H. Yakabe, T. Ogiwara, M. Hishinuma, and I. Yasuda, J. Power Sources, 102, 144 (2001).

8. S. B. Adler, J. A. Lane, and B. C. H. Steele, J. Electrochem. Soc., 143, 3554 (1996).

9. P. Costamagna, P. Costa, and V. Antonucci, Electrochim. Acta, 43, 375 (1998)

10. S. H. Chan and Z. T. Xia, J. Electrochem. Soc., 148, A388 (2001).

11. X. J. Chen, S. H. Chan, and K. A. Khor, Electrochim. Acta, 49, 1851 (2004).

12. S. H. Chan, X. J. Chen, and K. A. Khor, J. Electrochem. Soc., 151, A164 (2004).

13. S. Sunde, J. Electroceram., 5, 153 (2000).

14. A. M. Svensson, S. Sunde, and K. Nisancioglu, J. Electrochem. Soc., 144, 2719 (1997).

15. A. M. Svensson, S. Sunde, and K. Nisancioglu, J. Electrochem. Soc., 145, 1390 (1998).

16. J. Deseure, Y. Bultel, L. Dessemond, and E. Siebert, Electrochim. Acta, 50, 2037 (2005)

17. F. van Heuveln, Characterisation of Porous Cathodes for Application in Solid Oxide Fuel Cells, Ph.D. Thesis, University of Twente, Twente, Netherlands, 1997.

18. B. de Boer, Ph.D. Thesis, University of Twente, Netherlands, (1998).

19. J. Mizusaki, H. Tagawa, T. Saito, T. Yamamura, K. Kamitani, K. Hirano, S. Ehara, T. Takagi, T. Hikita, M. Ippommatsu, S. Nakagawa, and K. Hashimoto, Solid State Ionics, 70/71, 52 (1994).

20. A. Mitterdorfer and L. J. Gauckler, Solid State Ionics, 117, 187 (1999).

21. A. Mitterdorfer and L. J. Gauckler, Solid State Ionics, 117, 203 (1999).

22. A. Mitterdorfer and L. J. Gauckler, Solid State Ionics, 120, 211 (1999).

23. R. E. Williford and L. A. Chick, Surf. Sci., 547, 421 (2003).

24. A. Bieberle and L. J. Gauckler, Solid State Ionics, 146, 23 (2002)

25. W. G. Bessler, Solid State Ionics, 76, 997 (2005).

26. D. G. Goodwin, in Solid Oxide Fuel Cells IX, S. Singhal and J. Mizusaki, Editors, PV 2005-07, p. 699, The Electrochemical Society, Proceedings Series, Pennington, NJ (2005).

27. W. G. Bessler, S. Gewies, and J. Warnatz, Solid Oxide Fuel Cells IX, S. Singhal and J. Mizusaki, Editors, PV 2005-07, The Electrochemical Society, Proceedings Series, Pennington, NJ (2005).

28. H. Zhu and R. J. Kee, J. Power Sources, 117, 61 (2003)

29. K. M. Walters, A. M. Dean, H. Zhu, and R. J. Kee, J. Power Sources, 123, 182 (2003).

30. R. J. Kee, M. E. Coltrin, and P. Glarborg, Chemically Reacting Flow: Theory and Practice, John Wiley, New York (2003).

31. G. K. Gupta, E. S. Hecht, H. Zhu, A. M. Dean, and R. J. Kee, J. Power Sources, In press.

32. S. McIntosh and R. J. Gorte, Chem. Rev. (Washington, D.C.), 104, 4845 (2004).

33. C. Y. Sheng and A. M. Dean, J. Phys. Chem. A, 108, 3772 (2004).

34. E. A. Mason and A. P. Malinauskas, Gas Transport in Porous Media: The DustyGas Model, American Elsevier, New York (1983).

35. T. Thampan, S. Malhotra, H. Tang, and R. Datta, J. Electrochem. Soc., 147, 3242 (2000).

36. T. Thampan, S. Malhotra, J. Zhang, and R. Datta, Catal. Today, 67, 15 (2001).

37. R. J. Kee, G. Dixon-Lewis, J. Warnatz, M. E. Coltrin, and J. A. Miller, Technical Report SAND 86-8246, Sandia National Laboratories, 1986.

38. D. G. Goodwin, in Chemical Vapor Deposition XVI and EUROCVD 14, M. Allendorf, F. Maury, and F. Teyssandier, Editors, PV 2003-08, p. 155, The Electrochemical Society, Proceedings Series, Pennington, NJ, (2003); see also http:// www.cantera.org

39. J. Bear, Dynamics of Fluids in Porous Media, American Elsevier, New York (1972).

40. U. M. Ascher and L. R. Petzold, Computer Methods for Ordinary Differential Equations and Differential-Algebraic Equations, SIAM, Philadelphia, PA (1998).

41. R. J. Kee, F. M. Rupley, E. Meeks, and J. A. Miller, Technical Report SAND968216, Sandia National Laboratories (1996).

42. M. E. Coltrin, R. J. Kee, F. M. Rupley, and E. Meeks, Technical Report SAND968217, Sandia National Laboratories (1996)

43. M. C. J. Bradford and M. A. Vannice, Catal. Rev. - Sci. Eng., 41, 1 (1999)

44. J. Xu and G. F. Froment, AIChE J., 35, 88 (1989)

45. J. R. Rostrup-Nielsen, in CATALYSIS-Science and Technology, J. R. Anderson and M. Boudart, Editors, Vol. 5, Springer, New York (1984).

46. D. Chen, R. Lodeng, A. Anundskas, O. Olsvik, and A. Holmen, Chem. Eng. Sci, 56, 1371 (2001)

47. J. Wei and E. Iglesia, J. Catal., 224, 370 (2004).

48. L. M. Aparicio, J. Catal., 165, 262 (1997).

49. E. Shustorovich, Adv. Catal., 37, 101 (1990).

50. E. Shustorovich and H. Sellers, Surf. Sci. Rep., 31, 1 (1998).

51. A. T. Bell, in Metal Surface Reaction Energetics: Theory and Application to Heterogeneous Catalysis, Chemisorption and Surface Diffusion, E. Shustorovich, Editor, Chap. 5, John Wiley, New York (1991).

52. M. J. Hei, H. B. Chen, J. Yi, Y. J. Lin, Y. Z. Lin, G. Wei, and D. W. Liao, Surf. Sci., 417, 82 (1998) 
53. J. Lapujoulade and K. S. Neil, J. Chem. Phys., 57, 3535 (1972).

54. K. Christmann, O. Schober, G. Ertl, and M. Neumann, J. Chem. Phys., 60, 4528 (1974).

55. R. Schwiedernoch, S. Tischer, C. Correa, and O. Deutschmann, Chem. Eng. Sci., $\mathbf{5 8}, 633$ (2003)

56. B. Schädel, Master's Thesis, Dept. of Chemistry and Biosciences, University of Karlsruhe (2004).

57. N. Al-Sarraf, J. T. Stuckless, C. E. Wartnaby, and D. A. King, Surf. Sci., 283, 427 (1993).

58. L. L. Raja, R. J. Kee, O. Deutschmann, J. Warnatz, and L. D. Schmidt, Catal. Today, 59, 47 (2000)

59. O. Deutschmann and S. Tischer, Detchem Software Package, Technical Report. http://www.detchem.com, University of Karlsruhe (2004).

60. S. Tischer, C. Correa, and O. Deutschmann, Catal. Today, 69, 57 (2001)

61. E. S. Hecht, G. K. Gupta, H. Zhu, A. M. Dean, R. J. Kee, L. Maier, and O. Deutschmann, Appl. Catal., A, In press.
62. M. Mogensen and T. Lindegaard, in Solid Oxide Fuel Cells, p.484, S. Singhal and J. Mizusaki, Editors, PV 93-4, The Electrochemical Society, Proceedings Series, Pennington, NJ (1993)

63. P. Holtappels, L. G. J. de Haart, and U. Stimming, J. Electrochem. Soc., 146, 1620 (1999).

64. P. Holtappels, L. G. J. de Haart, and U. Stimming, J. Electrochem. Soc., 146, 2976 (1999).

65. A. Bieberle, Ph.D. Thesis, Swiss Federal Institute of Technology, Zürich (2000).

66. A. S. Ioselevich and A. A. Kornyshev, Fuel Cells, 1, 40 (2001).

67. M. Ihara, T. Kusano, and C. Yokoyama, J. Electrochem. Soc., 148, A209 (2001)

68. X. Wang, N. Nakagawa, and K. Kato, J. Electrochem. Soc., 148, A565 (2001).

69. R. J. Kee, H. Zhu, and D. G. Goodwin, Proc. Combust. Inst. 30, 2379 (2005).

70. J. O'M. Bockris and A. K. N. Reddy, Modern Electrochemistry. An Introduction to an Interdisciplinary Area, Plenum Press, New York (1970).

71. Y. Jiang and A. V. Virkar, J. Electrochem. Soc., 150, A942 (2003).

72. Y. Matsuzaki and I. Yasuda, Solid State Ionics, 126, 307 (1999). 